\title{
ALESSANDRA BARBAN
}

Análise da mobilização e resultados do transplante de células- tronco hematopoiéticas autogênico (TCTHa) com alta hospitalar precoce nos portadores de doenças hematológicas 


\section{ALESSANDRA BARBAN}

\section{Análise da mobilização e resultados do transplante de células- tronco hematopoiéticas autogênico (TCTHa) com alta hospitalar precoce nos portadores de doenças hematológicas}

Dissertação apresentada à Faculdade de Medicina da Universidade de São Paulo para a obtenção do título de Mestre em Ciências

Programa de Ciências Médicas

Área de concentração: Processos Imunes e Infecciosos

Orientador: Prof. Dr. Frederico Luiz Dulley

São Paulo 
Dados Internacionais de Catalogação na Publicação (CIP)

Preparada pela Biblioteca da

Faculdade de Medicina da Universidade de São Paulo

Creprodução autorizada pelo autor

\section{Barban, Alessandra}

Análise da mobilização e resultados do transplante de células-tronco hematopoiéticas autogênico (TCTHa) com alta hospitalar precoce nos portadores de doenças hematológicas / Alessandra Barban. -- São Paulo, 2013.

Dissertação(mestrado)--Faculdade de Medicina da Universidade de São Paulo. Programa de Ciências Médicas. Área de concentração: Processos Imunes e Infecciosos.

Orientador: Frederico Luiz Dulley.

Descritores: Transplante autólogo/enfermagem 2.Transplante de células-tronco de sangue periférico 3.Alta do paciente 4.Cuidados de enfermagem 5.Mobilização de células-tronco hematopoéticas 6.Avaliação de resultado de intervenções terapêuticas 7.Condicionamento pré-transplante/enfermagem 8.Toxicidade de drogas 9.Infecção 10.Resultado de tratamento 


\section{NORMALIZAÇÃO ADOTADA}

Esta dissertação está de acordo com as seguintes normas, em vigor no momento desta publicação:

Referências: adaptado de International Committee of Medical Journals Editors.

Universidade de São Paulo. Faculdade de Medicina. Divisão de Biblioteca e Documentação. Guia de apresentação de dissertações, teses e monografias. Elaborado por Anneliese Carneiro da Cunha, Maria Julia de A. L. Freddi, Maria F. Crestana, Marinalva de Souza Aragão, Suely Campos Cardoso, Valéria Vilhena. $3^{\text {a }}$ ed. São Paulo: Divisão de Biblioteca e Documentação; 2011.

Abreviaturas dos títulos dos periódicos de acordo com List of Journals Indexed in Index Medicus. 
Agradecimento Especial

Aos meus pais Márcia e José,

por toda dedicação, empenho e responsabilidade

na minha educação.

... por serem a minha inspiração de vida e a quem eu devo todo meu amor, admiração e gratidão. 


\section{Agradecimentos}

À Deus por ter permitido que um grande sonho se tornasse realidade.

Ao meu orientador, Prof. Dr. Frederico Luiz Dulley pela oportunidade, confiança e credibilidade a mim dedicados na confecção desta Dissertação e no crescimento profissional.

Ao Hospital das Clínicas da Faculdade de Medicina da Universidade de São Paulo, que me acolhe desde os meus tempos de estagiária e diariamente me proporciona um novo aprendizado.

À minha amiga Priscila Tavares Musqueira Cosenza pela imensa ajuda, companheirismo e apoio, sem os quais teria sido mais difícil concluir este estudo.

Ao amigo Fábio Luiz Coracin pela valiosa ajuda despendida ao longo desta dissertação e também pela contribuição para o meu crescimento profissional.

À minha irmã Andrea Barban pelo incentivo e por acreditar nos meus sonhos.

Ao amigo Carlos Henrique Moreira da Cunha por ter participado do início da coleta de dados.

À minha amiga Fabiane Almeida Mota Milanez por toda a preocupação e empenho.

Aos colegas de equipe do Ambulatório de TMO, pelo companheirismo, dedicação e confiança, especialmente ao colega Landri de Souza Júnior pela solicitude em retirar os prontuários no Setor de Arquivo Médico. 
Ao Serviço de Hematologia do HCFMUSP, na pessoa do Prof. Dr. Dalton de Alencar Fischer Chamone pela oportunidade em trabalhar na equipe e por acreditar na minha capacidade profissional.

À Divisão de Enfermagem do Instituto Central, na pessoa da Dra. Floracy Gomes Ribeiro, pela confiança, solicitude e atenção desde o fomento que fomos incorporados à esta Divisão.

À Enfermeira Celina Campos de Araújo, pelo estímulo presente, incentivo e interesse no desfecho desta dissertação.

Aos avaliadores da minha qualificação, Dr. Milton Arthur Ruiz, Dr. Alfredo Mendrone Júnior e Dr. José Eduardo Nicolau pelos valiosos apontamentos.

Aos pacientes, razão dos nossos estudos... 


\section{SUMÁRIO}

Lista de abreviaturas

Lista de símbolos

Lista de tabelas

Resumo

Abstract

1.INTRODUÇÃ

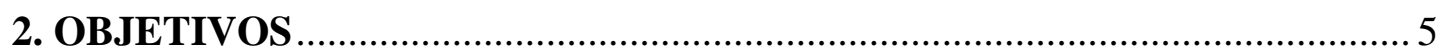

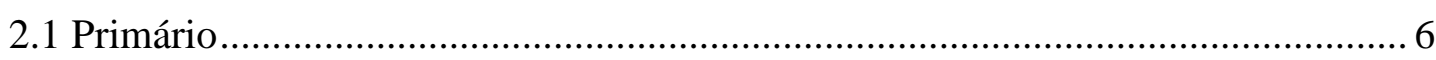

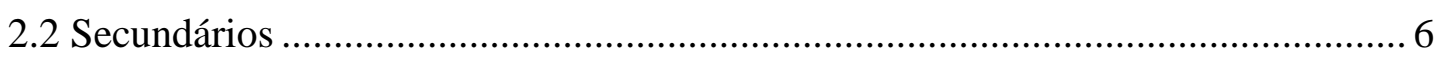

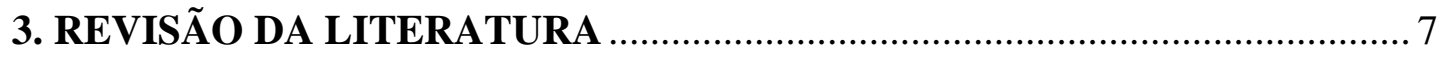

3.1 O transplante de células-tronco hematopoiéticas autogênico e a alta hospitalar precoce

3.2 O transplante de células-tronco hematopoiéticas e a alta precoce no Brasil e seu desenvolvimento no Hospital das Clínicas da Faculdade de Medicina da USP

3.3 A enfermagem e o transplante 12

3.4 Estadia do paciente durante o tratamento no Serviço ................................ 14

3.5 O papel do cuidador durante o TCTH............................................... 14

3.6 Mobilização e coleta das células-tronco hematopoiéticas periféricas ......... 15

3.7 Transplante de células-tronco hematopoiéticas ........................................ 18

3.7.1 Regime de condicionamento e toxicidades ................................. 18

3.7.2 Utilização de hemocomponentes durante o TCTH ......................... 19

3.7.3 Processos infecciosos associados ao TCTH .................................... 20

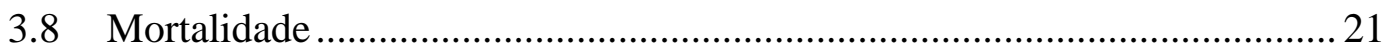

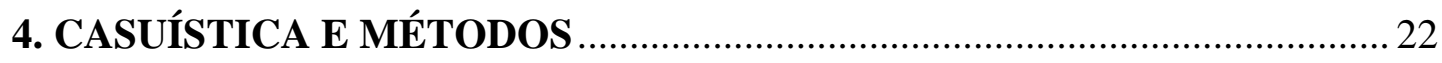

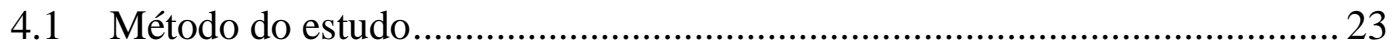

4.2 Critérios de inclusão e exclusão........................................................... 23 


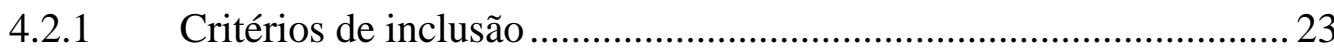

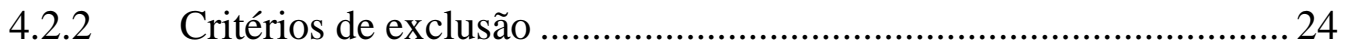

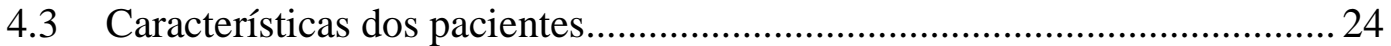

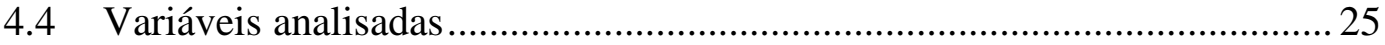

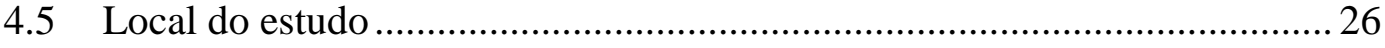

4.6 As fases do transplante de células-tronco hematopoiéticas no HC-FMUSP ..

4.6.1 Mobilização, coleta e criopreservação das células-tronco

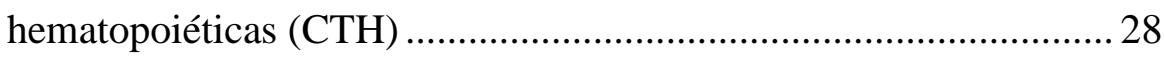

4.6.2 Regime de condicionamento e infusão das CTH ............................ 31

4.6.3 Critérios de alta hospitalar precoce …............................................ 32

4.6.4 Admissão do paciente no ambulatório de TCTH ............................ 33

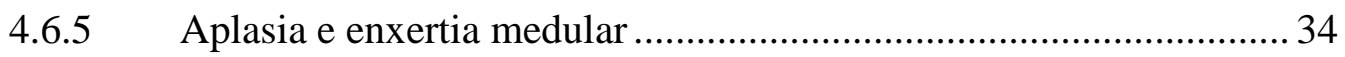

4.6.6 Hemoterapia - suporte transfusional pós TCTH............................... 34

4.6.7 Profilaxias bacteriana, viral e fúngica ............................................. 35

4.6.8 Critérios de internação por intercorrências........................................ 36

4.6.9 Mucosite, náusea/ vômito e diarreia.............................................. 37

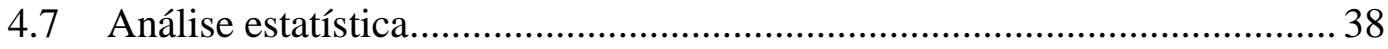

5. RESULTADOS

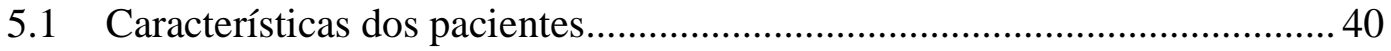

5.2 Distribuição dos pacientes em relação à doença ......................................... 40

5.3 Tratamento da doença de base previamente ao TCTH .............................. 42

5.4 Mobilização das CTH periféricas ............................................................. 44

5.5 Regimes de condicionamento para o TCTHa .......................................... 45

5.5.1 Toxicidades ao regime de condicionamento ................................ 46

5.5.2 Toxicidades relacionadas ao regime de condicionamento BEAM 400 
5.5.3 Toxicidades relacionadas ao regime de condicionamento BEAM... 48

5.5.4 Toxicidades relacionadas ao regime de condicionamento BU12/MEL100

5.5.5 Toxicidades relacionadas ao regime de condicionamento MEL 20050

5.5.6 Toxicidades relacionadas ao regime de condicionamento BU16/MEL140...................................................................... 50

5.5.7 Outros regimes de condicionamento com dose reduzida ................51

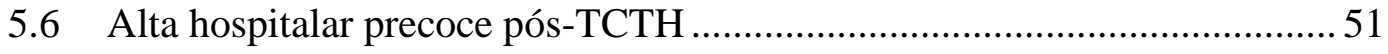

5.6.1 Local de estadia dos pacientes na fase ambulatorial após alta

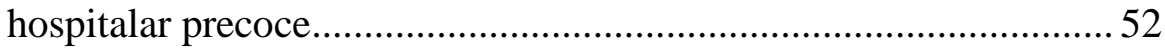

5.7 Enxertia dos granulócitos e plaquetas ........................................................53

5.8 Internação dos pacientes após alta hospitalar precoce ..................................55

5.9 Ocorrência de infecção pós-TCTH ..........................................................5

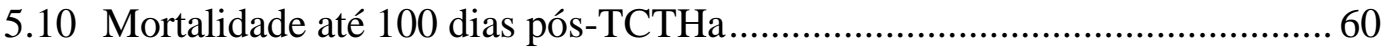

5.11 Tempo de permanência no Serviço pós-TCTHa............................................ 61

6. DISCUSSÃO

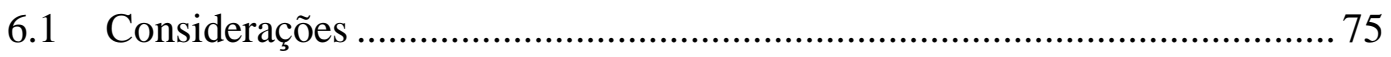

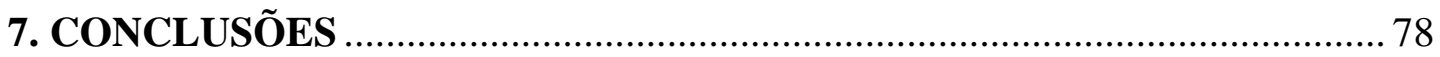

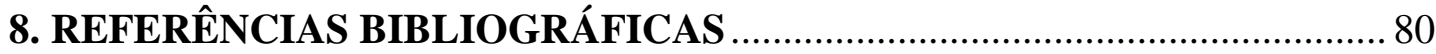

ANEXO I - Parecer de Aprovação do Comitê de Ética em Pesquisa........................ 92 


\section{LISTA DE ABREVIATURAS}

\begin{tabular}{ll} 
ACD & Adenina, Citrato e Dextrose \\
ANVISA & Agência Nacional de Vigilância Sanitária \\
BEAM & Bussulfano, Etoposide, Citarabina e Melfalano \\
BU & Bussulfano \\
cGy & Centigray \\
CTH & Células-Tronco Hematopoiéticas \\
CD34 & Células que expressam a molécula CD34 \\
CHI & Concentrado de hemácias irradiadas \\
CPAI & Concentrado de plaquetas por aférese irradiadas \\
CVC & Cateter Venoso Central \\
DECH & Doença do Enxerto Contra o Hospedeiro \\
DGCB & Linfoma Não-Hodgkin de Grandes Células B \\
Gy & Gray \\
FEV & Dimetilsulfóxido \\
Fram + & Feminino \\
\hline
\end{tabular}

HC-FMUSP Hospital das Clínicas da Faculdade de Medicina da Universidade de São Paulo

HDA Hemorragia Digestória Alta

HMC Hemocultura 


\begin{tabular}{|c|c|}
\hline $\mathrm{ICHC}$ & Instituto Central do Hospital das Clínicas \\
\hline ID & Identificação \\
\hline INCA & Instituto Nacional do Câncer \\
\hline InCor & Instituto do Coração \\
\hline IV & Via Intravenosa \\
\hline LMA & Leucemia Mielóide Aguda \\
\hline LH & Linfoma de Hodgkin \\
\hline LNH & Linfoma Não-Hodgkin \\
\hline M & Masculino \\
\hline MEL & Melfalano \\
\hline MM & Mieloma Múltiplo \\
\hline $\mathrm{N}^{\circ}$ & Número \\
\hline OMS & Organização Mundial da Saúde \\
\hline $\mathrm{RC}$ & Resposta Completa \\
\hline $\mathrm{RDC}$ & Resolução da Diretoria Colegiada \\
\hline $\mathrm{RP}$ & Resposta Parcial \\
\hline RT & Radioterapia \\
\hline SAE & Sistematização da Assistência de Enfermagem \\
\hline $\mathrm{SC}$ & Via Subcutânea \\
\hline SNT & Sistema Nacional de Transplantes \\
\hline SOS & Síndrome Obstrutiva Sinusoidal \\
\hline SUS & Sistema Único de Saúde \\
\hline $\mathrm{T}$ & Temperatura \\
\hline ТСТН & Transplante de células-tronco hematopoiéticas \\
\hline
\end{tabular}


TCTHa Transplante de células-tronco hematopoiéticas autogênico URO Urocultura

USP Universidade de São Paulo




\section{LISTA DE SÍMBOLOS}

\begin{tabular}{|c|c|}
\hline o & número ordinal \\
\hline${ }^{\circ} \mathrm{C}$ & graus Celsius \\
\hline $\mathrm{D}+$ & dia pós TCTH \\
\hline $\mathrm{kg}$ & quilograma \\
\hline $\mathrm{ml}$ & mililitro (s) \\
\hline $\mathrm{m}^{2}$ & metro quadrado \\
\hline $\mathrm{mm}^{3}$ & milímetro cúbico \\
\hline $\mathrm{x}$ & vez (es) \\
\hline+ & mais \\
\hline$\%$ & porcento \\
\hline$>$ & maior \\
\hline$<$ & menor \\
\hline$\geq$ & maior ou igual \\
\hline$\leq$ & menor ou igual \\
\hline- & negativo \\
\hline l & por \\
\hline$=$ & igual \\
\hline$\cong$ & aproximadamente igual \\
\hline $\mathrm{mg}$ & miligrama (s) \\
\hline $\mathrm{g}$ & grama (s) \\
\hline $\operatorname{mcg}$ & micrograma (s) \\
\hline $\mathrm{L}$ & litro (s) \\
\hline $\mathrm{dL}$ & decilitro (s) \\
\hline
\end{tabular}




\section{LISTA DE TABELAS}

Tabela 1 - Regimes de condicionamento utilizados nos pacientes submetidos ao TCTH de acordo com a doença de base (HC-FMUSP, 2009).

Tabela 2 - Escala de avaliação de toxicidade ao regime de condicionamento. 38

Tabela 3 - Dados demográficos dos pacientes submetidos ao TCTHa (jan a dez 2009) ..... 40

Tabela 4 - Distribuição dos pacientes de acordo com a doença 41

Tabela 5 - Subtipo das doenças dos pacientes submetidos ao TCTHa (jan a dez 2009) 41

Tabela 6 - Tratamento prévio à indicação do TCTH, de acordo com a doença 43

Tabela 7 - Tipo de resposta ao tratamento prévio ao TCTH de acordo com a doença 43

Tabela 8 - Resultados da mobilização das CTH periféricas 44

Tabela 9 - Regimes de condicionamento utilizados de acordo com a doença 46

Tabela 10 - Graduação das toxicidades após regime de condicionamento

Tabela 11 - Graduação das toxicidades relacionadas ao regime de condicionamento BEAM400. 48

Tabela 12 - Graduação das toxicidades relacionadas ao regime de condicionamento BU12/MEL 100

Tabela 13 - Alta hospitalar precoce até o D+10 52

Tabela 14 - Tipo de estadia após alta hospitalar da unidade de internação 53

Tabela 15 - Enxertia de granulócitos e plaquetas. 54 
Tabela 16 - Variação e mediana de transfusão de concentrado de hemácias e plaquetas do TCTHa até a alta do serviço $(\mathrm{N}=100)$

Tabela 17 - Frequência de internação hospitalar após alta hospitalar precoce 55

Tabela 18 - Etiologia das internações pós -TCTH com alta hospitalar precoce. 56

Tabela 19 - Micro-organismos presentes nas culturas dos pacientes até D+30 58

Tabela 20 - Classificação dos micro-organismos e sítios de coleta das culturas até o D+30 59

Tabela 21 - Micro-organismos encontrados nas culturas até o D+30 59

Tabela 22 - Diagnóstico, etiologia e tempo após o TCTHa dos pacientes que evoluíram para óbito em até 100 dias 60

Tabela 23 - Tempo de permanência no Serviço de TCTH até a alta do paciente 61 


\section{RESUMO}

Barban A. Análise da mobilização e resultados do transplante de células-tronco hematopoiéticas autogênico (TCTHa) com alta hospitalar precoce nos portadores de doenças hematológicas [Dissertação]. São Paulo: Faculdade de Medicina, Universidade de São Paulo; 2013.

O transplante de células-tronco hematopoiéticas autogênico (TCTHa) é um tratamento padrão utilizado para algumas doenças hematológicas e também na consolidação do tratamento de outras doenças. $\mathrm{O}$ aumento da demanda de pacientes que necessitam deste tratamento fez com que fossem criados alguns modelos de transplante ambulatorial. A alta precoce é uma modalidade de transplante em que o paciente recebe alta hospitalar após o regime de condicionamento e infusão das células-tronco hematopoiéticas (CTH) e a continuidade do seu tratamento ocorre em regime ambulatorial. Na área da Enfermagem, o número limitado de estudos científicos relacionados à Assistência de Enfermagem nos pacientes submetidos ao TCTH com alta hospitalar precoce são ainda deficientes. Diante disso, o objetivo deste estudo foi analisar os resultados da alta hospitalar precoce como alternativa viável ao tratamento dos pacientes submetidos ao TCTHa e sua relação com a assistência de enfermagem. MÉTODO: Estudo retrospectivo, quantitativo, descritivo e transversal. Foram analisados prontuários de 112 pacientes consecutivos submetidos ao TCTHa, no período de janeiro a dezembro de 2009. Destes 12 pacientes não receberam alta hospitalar da unidade de internação até o décimo dia após o TCTH (D+10) e, por isso, foram excluídos, restando 100 pacientes. RESULTADOS: A mediana de idade foi de 48,5 anos (19-69 anos). Houve um pareamento não intencional do sexo. Todos os pacientes mobilizaram e coletaram CTH por fonte periférica. Os regimes de condicionamento mais utilizados foram BU12+Mel100 e BEAM 400. As toxicidades atribuídas ao regime de condicionamento foram bem conduzidas no ambulatório, expressa por 10 pacientes que necessitaram de internação, embora um grande número de pacientes da casuística apresentou algum grau de toxicidade. A neutropenia febril esteve presente em $58 \%$ dos pacientes até a enxertia medular. Não houve aumento na mortalidade na fase de aplasia medular; dois pacientes foram a óbito por causas infecciosas durante os 60 primeiros dias após o TCTH, sendo que apenas um não apresentava enxertia medular. A mediana de enxertia de granulócitos após o TCTHa com alta hospitalar precoce foi de 12 dias e de plaquetas 15 dias, com mediana de transfusões até a alta do serviço de três concentrados de hemácias e quatro concentrados de plaquetas. Vinte e três pacientes necessitaram de internação hospitalar em algum momento desde a alta hospitalar após o transplante até o momento de sua alta. CONCLUSÃO: A equipe de enfermagem apresenta papel fundamental no contexto da alta hospitalar precoce na conduta e manejo dos pacientes. O Enfermeiro participou na orientação e condutas durante a fase de mobilização, transplante e acompanhamento ambulatorial. A mediana de tempo para enxertia medular foi de 12 dias e durante a fase de aplasia os pacientes evoluíram com baixa internação e infecção. Houve baixa incidência de complicações e internações, sendo a toxicidade ao regime de condicionamento a maior causa de internação. As toxicidades ao regime de condicionamento apresentadas foram bem manejadas em regime ambulatorial também pela Equipe de Enfermagem.

Descritores: 1.Transplante autólogo/enfermagem 2.Transplante de células-tronco de sangue periférico 3.Alta do paciente 4.Cuidados de enfermagem 5.Mobilização de células-tronco hematopoéticas 6.Avaliação de resultado de intervenções terapêuticas 7.Condicionamento pré-transplante/enfermagem 8.Toxicidade de drogas 9.Infecção 10.Resultado de tratamento 


\begin{abstract}
Barban A. Analysis of mobilization and autologous hematopoietic stem cells (HSCT) outcomes with early hospital discharge in patients with hematological diseases [Dissertation]. São Paulo: "Faculdade de Medicina, Universidade de São Paulo"; 2013.
\end{abstract}

The autologous hematopoietic stem cell transplantation (HSCTa) is a standard treatment used for some hematological malignancies and also in consolidating the treatment of other diseases. The increased number of patients who need this treatment leads to new models of outpatient transplant. The early discharge is a type of transplant in which the patient is discharged after the conditioning regimen and infusion of hematopoietic stem cells (HSC) and the continuity of your treatment will occur in outpatient settings. Although the models of outpatient HSCT are well defined, there is few studies and publications that demonstrate the actual results of this modality. In the field of nursing, the limited number of scientific studies related to nursing care in HSCT patients with early hospital discharge are even more deficient. Thus, the aim of this study was to analyze the results of early discharge as a viable alternative to the treatment of patients undergoing HSCTa and its relationship to nursing care. Methods: A retrospective, quantitative, descriptive and cross study was performed. A total of 112 patients initially enrolled, 12 were excluded due to the discharged occurred after than tenth day after HSCTa (D +10) and, therefore, 100 patients were enrolled in the study. Results: The median age was 48.5 years (range: 19-69 years). There was an unintentional pairing of sex. All patients were mobilized and collected by HSC peripheral source. The conditioning regimens were used more BU12 + Mel100 and BEAM 400. The conditioning regimen-related toxicities was well at the clinic, expressed by 10 patients who required hospitalization, although a large number of patients in the sample had some degree of toxicity. Febrile neutropenia was observed in $58 \%$ of patients until the marrow engraftment. There was no increase in mortality in bone marrow aplasia phase, two patients $(2 \%)$ died of infectious causes during the first 60 days after HSCTa, and only one patient showed no engraftment. The median granulocyte engraftment after HSCTa with early hospital discharge was 12 days and platelets 15 days, with a median transfusion until discharge from the service three and four units of blood transfused platelet concentrates. Twenty-three patients required hospitalization at some time from hospital discharge after transplantation until the time of his discharge. Conclusion: The nursing team has key role in the context of early hospital discharge in the conduct and management of patients. The nurse participated in the orientation and conduct during the mobilization phase, and outpatient transplant. The median time to engraftment was 12 days and during the aplasia phase of the patients improved, with low infection and hospitalization. There was a low incidence of complications and hospitalizations, and the toxicity conditioning regimen the leading cause of hospitalization. The toxicities presented to the conditioning regimen were well managed on an outpatient basis also for the Nursing Team.

Descriptors: Transplantation, autologus/nursing; Peripheral blood steam cell transplantation; Patient discharge; Nursing care; Hematopoietic stem cell mobilization; Evaluation of results of therapeutic interventions; Transplantation conditioning/nursing; Drug toxicity; Infection; Treatment outcome 
1. INTRODUÇÃO 
O transplante de células-tronco hematopoiéticas autogênico (TCTHa) é um tratamento padrão utilizado para algumas doenças hematológicas e também na consolidação do tratamento de outras doenças (Ferrara et al., 2004; Rosenbeck et al., 2010). É destinado à cura da maioria das doenças hematológicas malignas tais como, linfomas e leucemias, sendo a principal indicação nas leucemias resistentes aos tratamentos quimioterápicos (Bueno et al., 2011).

O TCTHa consiste em altas doses de quimioterapia, também denominado regime de condicionamento, objetivando a eliminação da doença e posterior infusão das células-tronco hematopoiéticas $(\mathrm{CTH})$ coletadas do próprio paciente, na tentativa de recompô-las após a aplasia medular secundária aos efeitos da quimioterapia (Grotto; Noronha, 2003; Armitage et al., 2009; Faucher et al., 2012). Este procedimento tem aumentado de modo expressivo, especialmente em países desenvolvidos. Estima-se que 30 a 50 mil transplantes sejam realizados anualmente em todo o mundo, e que este número aumente de $10-15 \%$ por ano. O registro europeu de TCTH apontou que, entre os anos de 2000 e 2001, foram realizados cerca de 5000 TCTH autogênicos, aumentando para 7000 em 2002 (Goldman; Horowitz, 2002).

O aumento da demanda de pacientes que necessitam de transplante de célulastronco hematopoiéticas (TCTH) fez com que alguns modelos de transplante ambulatorial fossem criados. A alta precoce é uma modalidade de transplante onde o paciente recebe alta hospitalar após o regime de condicionamento e infusão das células-tronco hematopoiéticas $(\mathrm{CTH})$ e a continuidade do seu tratamento ocorre em no ambulatório. No Brasil, esta modalidade teve como precursor o Hospital das Clínicas da Faculdade de Medicina da Universidade de São Paulo (HC-FMUSP), 
sendo reconhecido e regulamentado pela portaria $n^{\circ} 2041$ de setembro de 2008 do Ministério da Saúde, cuja permanência mínima do paciente internado para realização do transplante é de seis dias. As portarias brasileiras elaboradas pelo Ministério da Saúde são resultantes do aprimoramento de recursos científicos e tecnológicos, possibilitando aos pacientes o acesso ao TCTH com alta hospitalar precoce e não apenas restritos ao regime de internação.

Embora os modelos de TCTH ambulatorial sejam bem definidos, há uma escassez de dados relacionados ao número de estudos e publicações científicas que demonstrem os resultados efetivos desta modalidade. As limitações de estudos científicos relacionados à assistência de enfermagem nos pacientes submetidos ao TCTH com alta hospitalar precoce são ainda maiores. A prática de enfermagem neste tipo de tratamento requer conhecimento dos protocolos, entendimento da manifestação da doença, do tratamento e das complicações. O grande volume de informações é um desafio para os enfermeiros mais experientes e principalmente para os recém-formados. (Grant et al., 2005; Brown; Faltus, 2011).

O quantitativo da produção na enfermagem em transplante de medula óssea registrada em base de dados em relação à pós-graduação é discreto, entre 1997 e 2007 foram 19 produções, sendo 89,5\% nos cursos de mestrado e 10,5\% nos cursos de doutorado, no mesmo período, 18 artigos foram publicados em periódico brasileiro (Das Mercês; Erdmann, 2010).

Diante do exposto, os pacientes submetidos ao TCTH autogênico com alta hospitalar precoce podem receber benefícios relacionados à sua recuperação sem que, necessariamente, permaneçam sob regime de internação. Paralelamente, a 
assistência de enfermagem pode ser considerada um fator imprescindível no processo de saúde-doença dos pacientes submetidos ao TCTHa.

Nós conduzimos um estudo retrospectivo, quantitativo, descritivo e transversal, analisando prontuários de pacientes consecutivamente, buscando os resultados do TCTHa com alta hospitalar precoce e comparando à revisão da literatura, buscando identificar as principais implicações para a assistência de enfermagem. 
2. OBJETIVOS 


\subsection{Primário}

- Analisar os resultados da alta hospitalar precoce como alternativa viável ao tratamento dos pacientes submetidos ao TCTH autogênico e sua relação com a assistência de enfermagem.

\subsection{Secundários}

- Verificar as implicações para a assistência de enfermagem a partir dos resultados da alta hospitalar precoce;

- Verificar a evolução clínica dos pacientes durante o período de aplasia;

- Verificar a incidência de complicações e toxicidades ao regime de condicionamento no período ambulatorial;

- Verificar o número e as causas de internações pós-TCTH até a alta do serviço. 


\section{REVISÃO DA LITERATURA}




\subsection{O transplante de células-tronco hematopoiéticas autogênico e a alta hospitalar precoce}

O transplante de células-tronco hematopoiéticas autogênico (TCTHa) é um procedimento onde são administradas altas doses de agentes citotóxicos, resultando em mielossupressão prolongada, seguido pela infusão das células-tronco hematopoiéticas $(\mathrm{CTH})$ do próprio paciente, com o objetivo de reconstituir a hematopoiese e prevenir as citopenias prolongadas (Rosenbeck et al., 2010). A administração de altas doses de quimioterapia seguida pela infusão das célulastronco hematopoiéticas é uma opção de tratamento potencialmente curativo para leucemias agudas (Bueno et al., 2011) e para alguns tumores pediátricos (Westermann, et al., 1999). É, também indicado como tratamento de primeira linha para o mieloma múltiplo com idade e co-morbidade elegíveis (Bonassa; Gato, 2012). Da mesma forma, o TCTHa é considerado tratamento padrão na recaída dos linfomas de Hodgkin quimiossensíveis, bem como para linfomas não-Hodgkin intermediário e alto risco (Jones et al., 2008; Cortez, 2010; Bonassa; Gato, 2012).

A escassez de doadores compatíveis com o paciente motivou os pesquisadores a utilizar o TCTHa como modalidade de tratamento, visando a substituição da medula óssea alogênica ou singênica. Contudo, em temperatura ambiente, a medula óssea não manteria sua estabilidade e viabilidade por muito tempo, sendo necessário o desenvolvimento de técnicas de criopreservação e estocagem da medula óssea (Buckner, 1999). 
A criopreservação é um método de congelamento que utiliza o dimetilsulfóxido (DMSO) com o objetivo de crioproteger as células obtidas na coleta (Ock; Rho, 2011). O DMSO é relativamente permeável na membrana celular prevenindo a formação intracelular de cristais de gelo e a ruptura da membrana celular sob congelamento (Bakken, 2006).

Tradicionalmente, os pacientes internam para receber altas doses de quimioterapia, infusão das CTH e permanecem internados para seguimento por um período de três a cinco semanas (Grant et al., 2005; Faucher et al., 2012). A hospitalização durante a fase de aplasia gera altos custos e expõe o paciente a infecções nosocomiais, aumentando a ocupação de leitos hospitalares (Ferrara et al., 2004).

Nos últimos anos, houve uma diminuição das complicações referentes ao período de aplasia, a toxicidade ao regime de condicionamento e a mortalidade, viabilizando o TCTH com alta hospitalar precoce. Este declínio pode ser atribuído principalmente à mobilização das células-tronco hematopoiéticas periféricas, à administração de fatores de crescimento após a infusão das CTH, ao menor tempo para enxertia dos granulócitos e à melhora da terapia antimicrobiana profilática.

Ainda sobre os fatores que viabilizam a modalidade de alta hospitalar precoce, o tratamento antimicrobiano parenteral realizado no ambulatório, tem sido uma prática segura e viável graças à modernização dos cateteres intravenosos e outros dispositivos de infusão, como as bombas de infusão. (Morabito et al., 2002; Fernández-Avilés et al., 2006; Faucher et al., 2012).

Assim, os procedimentos e fases do TCTH que antes eram realizados exclusivamente em pacientes internados puderam, sem prejuízos, ser realizados em 
regime ambulatorial. Esta modalidade é descrita segundo três modelos de TCTH ambulatoriais:

- Na alta precoce: o paciente recebe o regime de condicionamento e a infusão das $\mathrm{CTH}$ internado e o seguimento posterior ocorre em regime ambulatorial.

- Na admissão tardia: o regime de condicionamento e a infusão das CTH são realizados ambulatorialmente e o paciente é internado apenas na fase de aplasia.

- No modelo totalmente ambulatorial: o TCTH e o seguimento pós-TCTH é realizado no ambulatório. A internação ocorre apenas se o paciente apresentar complicações (Peters et al., 1994; Weaver et al., 1997; Meisenberg et al., 1997a; Dix; Geller, 2000; Morabito et al., 2002; Ferrara et al., 2004).

\subsection{O transplante de células-tronco hematopoiéticas e a alta precoce no Brasil e seu desenvolvimento no Hospital das Clínicas da Faculdade de Medicina da USP}

Em 1979, o primeiro TCTH foi realizado no Hospital de Clínicas da Universidade Federal do Paraná, porém o paciente faleceu por hemorragia cerebral em poucos dias pós-TCTH, sem que fosse possível avaliar os resultados. Mediante ao insucesso do procedimento, os dirigentes do Hospital de Curitiba proporcionaram a uma pequena equipe, um estágio no Fred Hutchinson Cancer Research Center, em Seattle. Ao retornar em 1981, um segundo transplante foi realizado e bem sucedido, em um paciente com anemia aplástica, tornando-se assim, o primeiro paciente a ser 
submetido ao transplante de medula óssea com sucesso no Brasil e na América Latina. O Dr. Frederico Luiz Dulley, na época médico residente acompanhou o desfecho bem sucedido deste TCTH e foi especializar-se em Seattle. Após retornar ao Brasil, iniciou ao Serviço de TCTH do Hospital das Clínicas da Faculdade de Medicina da Universidade de São Paulo, em fevereiro de 1988. Com o passar dos anos, e com o desenvolvimento da ciência, as indicações do TCTH foram aumentando para diversas patologias, refletindo diretamente no número de pacientes que necessitavam desta modalidade de tratamento. Em 2000, iniciou-se a modalidade de TCTH com alta hospitalar precoce, apresentando um aumento de 30\% no número de pacientes que puderam ser beneficiados, diminuindo assim a longa espera por este procedimento. Até o ano de 2012 foram realizados 2.594 TCTH. Com a casuística do Serviço de Transplante de Medula Óssea do Hospital das Clínicas da Faculdade de Medicina de São Paulo foram realizadas 11 dissertações de mestrado, 13 teses de doutorado e uma livre docência até o ano de 2012.

Os Centros Transplantadores de CTH no Brasil, segundo dados do Sistema Nacional de Transplantes do Ministério da Saúde, contabilizavam até janeiro de 2009, 52 unidades para realização do TCTH autogênico, 36 para alogênicos aparentados e 15 para alogênicos não aparentados (Voltarelli, 2009). Estes números refletem um crescimento expressivo no país de pacientes beneficiados pelo transplante de células-tronco hematopoiéticas mostrando em 2009 a realização de 1.531 transplantes e em 2010 um aumento para 1695 transplantes realizados, representando um crescimento de $10,7 \%$ entre os anos avaliados e $74,38 \%$ desde 2003 (INCA, 2011). Ainda em 2009, foi realizada a primeira reunião envolvendo os principais Centros Transplantadores no intuito de criar o Consenso Brasileiro de 
transplante de células-tronco hematopoiéticas. Este Consenso buscou a padronização e a homogeneização na indicação e no tratamento para as diversas doenças e tipos de transplantes. Desde então, todos os Centros transplantadores passaram a seguir estas normatizações. No que se refere aos aspectos legais que regulamentam os procedimentos de TCTH no Brasil, é seguida a mesma hierarquia dos demais processos existentes no país, através de leis federais, portarias que aprovam o regulamento técnico e resoluções da diretoria colegiada (RDC) ditadas pela Agência Nacional de Vigilância Sanitária (ANVISA) e Sistema Nacional de Transplantes (SNT) (SBTMO, 2012).

\subsection{A enfermagem e o transplante}

Florence Nightingale é considerada mundialmente como a fundadora da enfermagem Moderna, obtendo projeção notória a partir de sua participação como voluntária na Guerra da Criméia, em 1854 (Padilha; Mancia, 2005; Costa et al., 2009). O trabalho que realizara durante a guerra alcançou uma dimensão maior do que simplesmente a ação de reorganizar a enfermagem e salvar vidas. Florence Nightingale, ainda, influenciou na reforma sanitária da Índia, nas melhores práticas de saúde do povo indígena da Austrália, nos avanços no controle da infecção e epidemiologia hospitalar, além de lições para a enfermagem moderna (Costa et al., 2009). 
As práticas relativas à infecção, iniciadas instintivamente por Florence, ao longo dos anos foram fundamentadas cientificamente e até o presente momento ainda são aplicáveis no cuidado ao paciente. A incidência de infecção após o TCTH é bastante significativa, impactando diretamente na morbidade e mortalidade. A equipe de enfermagem é imprescindível na implementação de práticas que previnam e combatam as infecções e seus efeitos associados ao TCTH (Bevans et al., 2009).

O TCTH é um tratamento de alta complexidade, que necessita da assistência de enfermagem integral em todas as etapas do processo: pré, intra e pós-transplante (Rimkus, 2009).

Segundo as estimativas do Instituto Nacional do Câncer (INCA) em 2012, houve um número crescente de pacientes portadores de doenças hematológicas, como leucemia, linfoma, e mieloma e submetidos ao transplante, fazendo com que o conhecimento baseado em evidências seja essencial ao enfermeiro, entendendo o processo de cuidar destes pacientes (Brown; Faltus, 2011).

O conhecimento das patologias com indicação de TCTH, a orientação aos pacientes e familiares e o monitoramento também são ações de enfermagem importantes no processo. A orientação ao paciente pode contribuir para o alcance das metas em longo prazo, através das necessidades em curto prazo. As alterações físicas, psicológicas, sociais e espirituais identificadas, podem ser usadas para descrever as intervenções a serem exploradas e testadas (Keogh et al.,1998; Broers et al., 2000; Fife et al., 2000). 


\subsection{Estadia do paciente durante o tratamento no Serviço}

A condição econômico-social dos pacientes pode ser um fator limitante na realização do transplante com alta hospitalar precoce.

Nesta modalidade, alguns Centros transplantadores usam também como critério, a proximidade do paciente com o hospital, onde o deslocamento não pode ultrapassar 60 minutos (Fernández-Ávilez et al., 2006).

Segundo Lipe et al (2012), em um estudo realizado com pacientes portadores de mieloma múltiplo e submetidos ao TCTHa, foi verificado que a distância do paciente em relação ao centro transplantador não seria uma barreira para o TCTH, porém o fato de estarem mais próximos ao hospital, devido ao acesso facilitado, faz com que busquem mais atendimento, incidindo em um aumento de riscos e complicações. Além disto, verificou maiores taxas de doenças crônicas e hospitalização por outros motivos não relacionados à doença (Lipe et al., 2012).

\subsection{O papel do cuidador durante o TCTH}

$\mathrm{O}$ paciente submetido à modalidade de TCTH com alta hospitalar precoce necessita de um cuidador que permaneça 24 horas por dia, todos os dias da semana (Fernández-Ávilez et al., 2006) e que seja treinado pela equipe de 
enfermagem no intuito de assistir ao paciente em suas atividades, acompanhá-lo ao hospital, administrar ou assegurar que o paciente receba as medicações prescritas, verificar os sinais vitais e para relatar qualquer anormalidade ou alteração (Frey et al., 2002) enquanto permanece em ambiente extra-hospitalar.

\subsection{Mobilização e coleta das células-tronco hematopoiéticas periféricas}

O processo de recrutamento das células-tronco periféricas da medula óssea para a circulação sanguínea após tratamento quimioterápico é denominado mobilização (Cottler-Fox et al., 2003; Mendrone, 2007a). Este termo será utilizado até o final desta dissertação.

A utilização das CTH periféricas iniciou-se em meados de 1980 e gradativamente substituiu a medula óssea nos TCTH autogênicos (Mendrone et al., 2008b; Wuchter et al., 2010). O recrutamento e coleta das CTH periféricas tem sido o tratamento de escolha para os pacientes portadores de linfomas e leucemias agudas. (Bhatia et al., 2005).

Inicialmente, a mobilização era realizada apenas com quimioterápicos, que potencializam a diminuição do tumor (Körbling et al., 1986; To et al., 1987a; Wuchter et al., 2010) e provocam uma mielossupressão transitória com leucopenia entre o sétimo e décimo quarto dia após sua administração, seguido por um rápido aumento dos leucócitos, aumentando o número das CTH no sangue periférico (Mendrone, 2009c) e por conseguinte, aumentando significativamente o número de 
células CD34+ no sangue periférico (Reiffers et al., 1986; Körbling et al., 1986; To et al., 1987a). Em contrapartida, as limitações deste tipo de mobilização incluem a toxicidade, o insucesso na mobilização e até a possibilidade de internação (Jagasia et al., 2011). O uso de fatores de crescimento, como o fator estimulador de colônia de granulócitos (G-CSF), após a quimioterapia mostrou-se eficiente na mobilização das CTH (To et al., 1997b), podendo aumentar em até 6\% as células CD34+ (Arslan; Moog, 2007).

O G-CSF é o fator de crescimento indicado há mais de duas décadas para mobilizar as CTH da medula óssea. Espera-se que o uso das doses entre cinco e 20 $\mathrm{mcg} / \mathrm{kg} / \mathrm{dia}$, sejam suficientes para realizar o recrutamento das células para a circulação periférica (Cottler-Fox et al., 2003; Ozcelik T, et al., 2009; Özkurt et al., 2010). Na tentativa de buscar melhores resultados no regime de mobilização, novos fármacos estão disponíveis. O plerixafor é um novo agente farmacológico utilizado para mobilizar as células-tronco no sangue. Em dois grandes estudos randomizados (DiPersio et al., 2009a; DiPersio et al., 2009b), o plerixafor associado ao G-CSF foi mais eficiente do que apenas o G-CSF nos pacientes com mieloma múltiplo e linfomas (Jantunen et al., 2012).

As células-tronco hematopoiéticas mobilizadas são coletadas através de um procedimento realizado por equipamentos automatizados. A predileção pela coleta das CTH por fonte periférica justifica-se pela facilidade e vantagens: em sua obtenção, pela diminuição na duração da neutropenia, do tempo de enxertia após altas doses de quimioterapia seguida pela infusão das CTH e, também, no número de transfusões (Champlin et al., 2000; Rosenbeck et al., 2010), pela diminuição da morbidade, devido a possibilidade de realizar o procedimento sem a necessidade de 
anestesia, pois o procedimento é indolor, se comparado às múltiplas aspirações da crista ilíaca quando utilizado o procedimento habitual, pela diminuição das infecções documentadas em comparação às células coletadas da medula óssea, do uso de antibióticos e dos dias de internação (Cotller-Fox et al., 2003; Grotto; Noronha, 2003; Özkurt et al., 2010; Wuchter et al., 2010). Em contrapartida, a principal desvantagem é que as CTH periféricas existem na circulação sanguínea em um número pequeno. Menos do que 0,06\% dos leucócitos são células CD34+ (Arslan; Moog, 2007; Wuchter et al., 2010).

A coleta de um número adequado de $\mathrm{CTH}$ é um pré-requisito para o TCTHa. $\mathrm{O}$ número de células-tronco considerado ideal para realização do TCTH é 5,0 x $10^{6}$ células CD34+/kg de peso, porém, o mínimo necessário para o TCTH deve ser acima de 2,0 x $10^{6}$ células CD34+/kg de peso (Özkurt et al., 2010; Jantunen et al., 2012; Sheppard et al., 2012).

Embora a coleta periférica das $\mathrm{CTH}$ seja uma prática bem definida, alguns pacientes não conseguem mobilizar um número suficiente de células para o TCTHa (Gordan et al, 2003; Kuittinen et al, 2004; Wuchter et al., 2010). Aproximadamente, cinco a $40 \%$ dos pacientes não mobilizam o mínimo necessário para a realização do TCTH (Özkurt et al., 2010; Mohty; Ho, 2011; Jantunen et al., 2012; Sheppard et al., 2012) e até o momento, ainda não há uma definição consensual sobre a mobilização insuficiente das CTH (Wuchter et al., 2010).

Algumas variáveis são importantes na coleta das CTH e podem estar relacionadas ao procedimento ou ao paciente. As variáveis relacionadas ao procedimento incluem o cateter venoso central (CVC) e ao paciente, a idade avançada, quimioterapia citotóxica prévia, regime de mobilização e a contagem de 
plaquetas no momento da mobilização (Cottler-Fox et al., 2003; Wuchter et al., 2010; Özkurt et al., 2010).

\subsection{Transplante de células-tronco hematopoiéticas}

3.7.1 Regime de condicionamento e toxicidades

Os regimes de condicionamento incluem altas doses de quimioterapia associadas ou não a radioterapia e antecedem ao TCTHa. O objetivo de sua utilização deve-se a necessidade de superar a resistência dos tumores à quimioterapia.

As doses elevadas de quimioterápicos correspondem a cerca de $20 \%$ da mortalidade precoce relacionada ao pós-TCTH (Vriesendorp, 2003). Os fármacos utilizados nos regimes de condicionamento, em geral, incluem um ou mais agentes alquilantes (Vriesendorp, 2003; Bacigalupo et al., 2009).

As graduações das toxicidades podem facilitar a comparação entre os regimes de condicionamento, além de permitir a distinção entre toxicidades e complicações relacionadas ao TCTH (Bearman et al., 1988).

As toxicidades relacionadas ao regime de condicionamento são mais frequentes no fígado, na mucosa oral e trato gatrointestinal (Bearman et al., 1988). A mucosite 
oral é um evento adverso comum e debilitante nos pacientes que recebem doses elevadas de quimioterapia, resultando tanto em danos epiteliais como também em tecidos da submucosa e podem interferir nas atividades diárias dos pacientes como falar, comer e deglutir, impactando negativamente na qualidade de vida (McCann et al., 2009). A colite neutropênica é uma complicação que pode ocorrer durante a neutropenia em 0,8 a $26 \%$ dos pacientes, variando de acordo com a definição e critérios clínicos diagnósticos de cada Centro (Salazar et al., 1999).

\subsubsection{Utilização de hemocomponentes durante o TCTH}

A transfusão de hemocomponentes é um procedimento habitual e necessário na fase de aplasia medular após o regime de condicionamento e TCTH.

Alguns estudos demonstram que o número de células CD 34+ infundidas após o condicionamento, apresentam uma relação direta com o tempo de neutropenia e algumas vezes também o tempo de enxertia plaquetária (Rosenbeck et al., 2010).

$\mathrm{O}$ uso das $\mathrm{CTH}$ periféricas ao invés da medula óssea tem diminuído substancialmente a duração da trombocitopenia. Ainda não há um consenso sobre a necessidade de transfusão profilática de plaquetas (Wandt et al., 2006). 


\subsubsection{Processos infecciosos associados ao TCTH}

A infecção é a maior causa de morbidade e mortalidade nos pacientes pósTCTH e tem sido uma das principais causas de hospitalização por intercorrências nos pacientes transplantados (Grant et al., 2005; Moya et al., 2006; Bevans et al., 2009).

Embora haja avanços na prevenção e no tratamento das doenças infecciosas na última década (Mendes et al., 2012), as complicações infecciosas, ainda são significativas nos pacientes que recebem altas doses de quimioterapia seguido pelo TCTHa, sendo relatada como a principal causa de morte em $8 \%$ dos pacientes submetidos a este procedimento (Gil et al., 2007; Tomblyn et al., 2009; Santos et al., 2012). A antibioticoterapia é um tratamento associado à neutropenia severa com duração de duas a três semanas (Gil et al., 2007). Neste período há um rompimento da barreira mucocutânea, propiciando o desenvolvimento de infecções (Santos et al., 2012).

Wingard et al. (2011) classifica o risco de infecção em 3 períodos:

- Antes da enxertia: a preocupação principal é com a neutropenia e a lesão da mucosa. A neutropenia após o regime de condicionamento mieloablativo no TCTHa, em média, permanece por 10 a 14 dias. O risco de infecção é causado principalmente por bactérias gram negativas, fungos e vírus da família Herpesviridae.

- Pós-enxertia precoce (até três meses pós-TCTH): período definido como a progressiva recuperação imunológica. Após o TCTHa, as infecções são frequentemente relacionadas às bactérias gram positivas e ao cateter venoso 
central (CVC). As infecções causadas por bactérias gram negativas também podem ocorrer em menor número.

- Pós-enxertia tardia (após três meses do TCTH): o risco de infecções oportunistas ocorre em menor proporção nos pacientes autogênicos. As infecções tardias são causadas por patógenos similares ao período de pósenxertia recente, acrescidos de bactérias encapsuladas e vírus varicela zoster.

Nos pacientes transplantados, a infecção é a complicação mais comum após a alta hospitalar e uma razão para a readmissão. A infecção é normalmente atrelada às alterações gastrointestinais e desidratação. Alguns aspectos importantes destes sinais devem ser parte do conteúdo de ensino e monitoramento na alta hospitalar dos pacientes e cuidadores. Tal ensino deve incluir metas específicas para pacientes e abordagens práticas úteis no ambiente doméstico (Grant et al., 2005).

\subsection{Mortalidade}

A aplasia medular, hábitos de higiene, alimentação, fatores sociais, etc., são complicações comuns ao transplantado de células-tronco hematopoiéticas e estão associadas ao alto risco de morbidade e mortalidade (Mank A; Van Der Lelie, 2003a). A mortalidade relacionada ao tratamento é um risco consideravelmente alto se comparado a outros procedimentos, variando entre três a 50\% (Appelbaum, 1996; Rowlings et al., 1996; Loberiza Jr et al., 2005). 
4. CASUÍSTICA E MÉTODOS 


\subsection{Método do estudo}

Este estudo foi aprovado pela Comissão de Ética para Análise de Projetos de Pesquisa (CAPPESQ) do Hospital das Clínicas da FMUSP com o número 0394/10 (Anexo A) e está dentro dos preceitos da declaração de Helsinki V e da Resolução 196/96 do Conselho Nacional de Saúde.

Trata-se de um estudo retrospectivo, quantitativo, descritivo e transversal. Os prontuários dos pacientes que foram submetidos ao transplante de células-tronco hematopoiéticas autogênico no ano de 2009, foram selecionados consecutivamente e deles obtidos os dados deste estudo.

\subsection{Critérios de inclusão e exclusão}

4.2.1 Critérios de inclusão

- Pacientes portadores de MM, LH, LNH e LMA;

- Alta hospitalar da unidade de internação até o décimo dia após o TCTH $(\mathrm{D}+10)$;

- Idade entre 18 e 70 anos;

- Acompanhamento ambulatorial dos pacientes até a alta do Serviço. 


\subsubsection{Critérios de exclusão}

- Outras doenças que não aquelas informadas nos critérios de inclusão;

- Pacientes submetidos ao TCTH alogênico;

- Alta hospitalar da unidade de internação posterior ao décimo dia pós TCTH;

- Idade inferior a 18 anos.

\subsection{Características dos pacientes}

Foram avaliados 112 pacientes submetidos ao TCTHa no Hospital das Clínicas da Faculdade de Medicina da Universidade de São Paulo (HC-FMUSP) no período de 05.01.2009 a 07.12.2009 para inclusão no estudo.

Destes, cem pacientes preencheram os critérios de inclusão e foram inseridos no estudo. Os 12 pacientes restantes não receberam alta hospitalar da unidade de internação até o décimo dia após o TCTH (D+10) e, por isso, foram excluídos.

A casuística compreendeu 45 pacientes portadores de mieloma múltiplo (MM), 21 pacientes portadores de linfoma de Hodgkin ( $\mathrm{LH}), 25$ pacientes portadores de linfoma não Hodgkin (LNH) e nove pacientes com o diagnóstico de leucemia mielóide aguda (LMA), submetidos ao transplante autogênico de células-tronco hematopoiéticas e que foram acompanhados no ambulatório do Serviço de 
Transplante de Células-Tronco Hematopoiéticas do Hospital das Clínicas da Faculdade de Medicina da Universidade de São Paulo (HC-FMUSP).

O paciente foi encaminhado ao Serviço de Transplante de Células-Tronco Hematopoiéticas do HC-FMUSP, avaliado inicialmente na primeira consulta médica com revisão de todos os exames realizados desde o diagnóstico da doença, incluindo a revisão das lâminas com os cortes histopatológicos utilizados no diagnóstico da doença de base. Todos os pacientes foram transplantados nas unidades de internação situadas no Instituto Central do Hospital das Clínicas (ICHC) e no Instituto do Coração (InCor), ambos fazendo parte do Complexo Hospitalar do Hospital das Clínicas da Faculdade de Medicina da USP. Os dados coletados abrangeram desde a fase da mobilização até a alta médica do Serviço.

\subsection{Variáveis analisadas}

As informações coletadas e analisadas obtidas em todos os prontuários foram:

1. Idade, sexo e raça;

2. Doença, tipo de resposta e data do diagnóstico;

3. Tratamentos prévios ao TCTHa;

4. Mobilização das células-tronco hematopoiéticas com quimioterápicos e G-CSF e apenas com G-CSF;

5. Período de mobilização;

6. Contagem periférica do número de células CD34+; 
7. Número de células CD34+ obtidas na coleta das CTH, fonte de obtenção e contagem de células CD34+ do produto;

8. Regime de condicionamento empregado;

9. Data da alta hospitalar;

10. Tempo de enxertia de granulócitos e plaquetas;

11. Número de transfusões desde o TCTH até a alta do Serviço;

12. Complicações infecciosas até o trigésimo dia pós-TCTH;

13. Principais toxicidades após transplante até a alta do Serviço;

14. Internação pós-TCTH;

15. Causa da internação;

16. Data do óbito e causa do óbito.

\subsection{Local do estudo}

O Serviço de TCTH do HC-FMUSP iniciou suas atividades em 1988 e é considerado um Serviço de excelência e referência no Brasil para tratamentos de doenças onco-hematológicas e recebe pacientes através do Sistema Único de Saúde (SUS) provenientes do Estado de São Paulo e, também, de outros estados brasileiros. Até dezembro de 2012, o Serviço realizou 2.595 transplantes, sendo 1.334 autogênicos e 1.261 alogênicos.

Atualmente, o Serviço de TCTH possui uma unidade hospitalar de internação com 19 leitos para realização do regime de condicionamento, infusão das células- 
tronco hematopoiéticas e retaguarda para eventuais internações. Possui também, um ambulatório que centraliza o atendimento dos pacientes pré-transplante e dos que estão em acompanhamento após a alta hospitalar. Os serviços do ambulatório são divididos em dois turnos de atendimento diário entre 7:00 e 19:00 horas. Neste período são realizadas consultas multiprofissionais, procedimentos de biópsia de medula óssea, mielograma, retirada de cateter venoso central e atendimentos de enfermagem. Os atendimentos de enfermagem incluíram monitorização clínica e laboratorial, Sistematização da Assistência de Enfermagem (SAE), admissão e encaminhamento para outras unidades, visitas diárias junto à equipe multiprofissional, suporte medicamentoso e transfusional, palestras e orientações aos pacientes e cuidadores.

A equipe de enfermagem do ambulatório apresentou grande responsabilidade no processo desde o início do TCTH, pois acompanhou todo o tratamento com bastante rigor na identificação das necessidades humanas. A orientação, vigilância e cuidados específicos ao paciente transplantado em regime ambulatorial foram necessários até a alta do Serviço em relação à saúde, imunidade e até aspectos culturais e de higiene.

Com objetivo de inserir os pacientes nas rotinas, procedimentos e normas do Ambulatório de TCTH, cada paciente recebeu uma apostila contendo orientações sobre alimentação, higiene, cuidados com o cateter venoso central, toxicidade aos agentes quimioterápicos após a mobilização/regime de condicionamento, rotinas da Unidade e contatos telefônicos em caso de dúvidas e necessidades.

Do ponto de vista social, os pacientes submetidos ao TCTH com alta hospitalar precoce necessitaram de uma estrutura eficiente para que se mantenham próximos ao 
Hospital em caso de intercorrências ou que possuam fácil locomoção. Para os pacientes residentes em outros municípios, estados ou até mesmo de bairros distantes ao Hospital, a estrutura social oferecida foi à Casa de Apoio, entidade filantrópica que possui uma área destinada exclusivamente aos pacientes que estão em processo de TCTH e conta com uma estrutura diferenciada com estadia para os pacientes e cuidadores, alimentação supervisionada por nutricionista, terapia ocupacional, psicologia, transporte diário em micro-ônibus e inclusive em ambulância, se necessário.

\subsection{As fases do transplante de células-tronco hematopoiéticas no HC-FMUSP}

4.6.1 Mobilização, coleta e criopreservação das células-tronco hematopoiéticas $(\mathrm{CTH})$

Os protocolos de mobilização das CTH foram realizados de acordo com a doença de base a ser tratada. No Serviço de TCTH do HC-FMUSP, o regime de mobilização mais comumente empregado para os pacientes portadores de LMA, LH, LNH e MM é a ciclofosfamida $120 \mathrm{mg} / \mathrm{kg} /$ peso. Em meados de 2009, um novo protocolo para mobilização dos pacientes portadores de LH foi empregado e utilizou ciclofosfamida $120 \mathrm{mg} / \mathrm{kg} /$ peso e gencitabina $2 \mathrm{~g} / \mathrm{m}^{2}$, sendo que ambos os protocolos foram divididos igualmente por dois dias consecutivos e com intervalo de 24 horas 
entre as doses. Independente do regime de mobilização empregado, todos os pacientes receberam por via subcutânea diariamente fator estimulador de colônia de granulócitos (G-CSF), na dose de 10 a $20 \mathrm{mcg} / \mathrm{kg}$ de peso, sendo a dose decidida a julgamento do médico e iniciada quando a contagem de leucócitos no sangue periférico fosse $\leq 1,0 \times 10^{3} / \mathrm{L}$ até a obtenção de CTH em número suficiente para a realização do transplante.

Nos pacientes portadores de mieloma múltiplo, com contagem de plasmócitos $<5 \%$ na medula óssea, a mobilização das CTH consistiu apenas no uso de G-CSF na dose de 10 a $20 \mathrm{mcg} / \mathrm{kg}$ de peso. A dose diária total de G-CSF foi fracionada em duas vezes no dia e administradas pelos profissionais da equipe de enfermagem do Ambulatório do Serviço de TCTH do HC-FMUSP. Os critérios de resposta completa foram baseados em Durie (Durie et al., 2006) consistindo de imunofixação negativa no soro e na urina, desaparecimento de plasmocitoma em tecidos moles e $\leq 5 \%$ de plasmócitos na medula óssea.

Quando a quantificação de leucócitos totais foi >1,0 x 103/L, iniciou-se a coleta diária de amostras de sangue (exceto aos domingos, quando o laboratório não realizava atividades) para contagem das células CD34+ no sangue periférico. Quando a contagem mostrou valores iguais ou superiores a 10 células $/ \mathrm{mm}^{3}$, a coleta por leucaférese foi iniciada no Setor de Aférese do HC-FMUSP. A coleta das CTH foi realizada por acesso venoso central, pelo sistema de aférese e através do equipamento Cobe Spectra (COBE®, Caridian-Terumo BTC, USA) e conforme procedimento padronizado pelo fabricante.

O processamento da coleta das $\mathrm{CTH}$ foi padronizado de duas a cinco volemias de sangue do paciente com o objetivo de obter um número absoluto $\geq 2,0 \times 10^{6}$ de 
células CD34+/kg de peso. A volemia foi calculada individualmente em função do peso, altura e sexo. Quando o número necessário das CTH para o transplante não foi alcançado apenas em uma coleta, outras foram realizadas até a obtenção do número de células para o transplante.

A solução de ACD (adenina, citrato e dextrose) foi padronizada na anticoagulação do circuito extracorpóreo durante a leucaférese, no volume de $1 \mathrm{ml}$ para cada $12 \mathrm{ml}$ de sangue total do paciente. Após o processamento, as bolsas contendo as CTH e uma amostra deste material foi encaminhada para o Setor de Criopreservação com o objetivo de quantificar o número absoluto de células na bolsa e promover a conservação das CTH até que fossem infundidas. Outra amostra foi encaminhada ao setor de bacteriologia para análise da hemocultura.

O produto obtido da coleta foi processado pelo Laboratório de Criopreservação, em um intervalo de até seis horas após sua obtenção.

O dimetilsulfóxido (DMSO) foi adicionado à bolsa de transferência para conservação e crioproteção das células coletadas em uma concentração final de $10 \%$ e submetida ao resfriamento para redução da temperatura pelo aparelho Cryomed modelo 1010 (Forma Scientific, Marietta, OH, USA) através de protocolo padronizado pelo fabricante, até atingir a temperatura de oitenta graus Celsius negativos $\left(-80^{\circ} \mathrm{C}\right)$. A redução da temperatura foi feita de um grau Celsius por minuto até chegar aos $40{ }^{\circ} \mathrm{C}$ negativos. A partir desta temperatura, a redução passou a ser de $10{ }^{\circ} \mathrm{C} /$ minuto até que atingisse $80{ }^{\circ} \mathrm{C}$ negativos. Ao término do congelamento, transferiram-se as bolsas contendo o produto criopreservado para um freezer mecânico cuja temperatura de estocagem alcança $120^{\circ} \mathrm{C}$ negativos e permaneceram estocadas até o momento da infusão. 
4.6.2 Regime de condicionamento e infusão das CTH

Os pacientes receberam o regime de condicionamento internados. $\mathrm{O}$ regime de condicionamento consistiu em altas doses de quimioterapia e variaram de acordo com o protocolo do Serviço. A determinação de cada regime de condicionamento foi baseada na doença a ser tratada, conforme Tabela 1.

Tabela 1 - Regimes de condicionamento utilizados nos pacientes submetidos ao TCTH de acordo com a doença de base (HC-FMUSP, 2009).

\begin{tabular}{|c|c|c|}
\hline Regime de condicionamento & Fármaco e doses & Doença \\
\hline $\begin{array}{l}\text { Bussulfano e Melfalano } \\
\qquad(\mathrm{N}=41)\end{array}$ & $\begin{array}{l}\text {-Bussulfano } 3 \mathrm{mg} / \mathrm{kg} / \mathrm{dia} / \text { 4dias } \\
\text {-Melfalano } 100 \mathrm{mg} / \mathrm{m}^{2}\end{array}$ & MM \\
\hline $\begin{array}{l}\text { Melfalano } \\
\qquad(\mathrm{N}=2)\end{array}$ & -Melfalano $200 \mathrm{mg} / \mathrm{m}^{2}$ & MM \\
\hline $\begin{array}{l}\text { BEAM } 400 \\
\qquad(\mathrm{~N}=36)\end{array}$ & $\begin{array}{l}\text {-Carmustina } 400 \mathrm{mg} / \mathrm{m}^{2} \\
\text {-Etoposide } 400 \mathrm{mg} / \mathrm{m}^{2} / \mathrm{dia} / 4 \text { dias } \\
\text {-Citarabina } 400 \mathrm{mg} / \mathrm{m}^{2} / \mathrm{dia} / 4 \text { dias } \\
\text {-Melfalano } 140 \mathrm{mg} / \mathrm{m}^{2}\end{array}$ & $\begin{array}{l}\mathrm{LH} \\
\mathrm{LNH}\end{array}$ \\
\hline $\begin{array}{l}\text { BEAM } \\
(\mathbf{N}=\mathbf{1 0})\end{array}$ & $\begin{array}{l}\text {-Carmustina } 300 \mathrm{mg} / \mathrm{m}^{2} \\
\text {-Etoposide } 200 \mathrm{mg} / \mathrm{m}^{2} / \mathrm{dia} / 4 \text { dias } \\
\text {-Citarabina } 400 \mathrm{mg} / \mathrm{m}^{2} / \mathrm{dia} / 4 \text { dias } \\
\text {-Melfalano } 140 \mathrm{mg} / \mathrm{m}^{2}\end{array}$ & $\begin{array}{l}\mathrm{LH} \\
\mathrm{LNH}\end{array}$ \\
\hline $\begin{array}{l}\text { Bussulfano e Melfalano } \\
\qquad(\mathrm{N}=7)\end{array}$ & $\begin{array}{l}\text {-Bussulfano } 4 \mathrm{mg} / \mathrm{kg} / \mathrm{dia} / 4 \mathrm{dias} \\
\text {-Melfalano } 140 \mathrm{mg} / \mathrm{m}^{2}\end{array}$ & LMA \\
\hline
\end{tabular}


O TCTHa foi realizado após 24 horas do término do regime de condicionamento. As células-tronco hematopoiéticas criopreservadas foram infundidas nos pacientes após descongelamento das bolsas de transferência. O descongelamento das bolsas contendo as CTH ocorreu imediatamente à infusão, à beira-leito e em banho-maria com temperatura controlada de $37^{\circ} \mathrm{C}$ até o total descongelamento.

As CTH foram administradas por via intravenosa em uma velocidade média de cinco mililitros por minuto em equipo para componentes sanguíneos, apirogênico e monitorizada rigorosamente pela equipe médica e de enfermagem.

Por convenção, o dia da infusão das CTH ou o dia do TCTH foi considerado o “dia zero". Os dias que antecedem o transplante foram definidos como "negativos" (D-) e os que sucedem foram denominados como "positivos" (D+).

4.6.3 Critérios de alta hospitalar precoce

Após a infusão das CTH, a alta hospitalar dos pacientes submetidos ao TCTHa foi programada respeitando dois critérios:

- Portaria no 2041 de setembro de 2008 do Ministério da Saúde que estipula, no mínimo, seis dias de internação para pacientes submetidos ao TCTH autogênico;

- Condições clínicas favoráveis ao seguimento em regime ambulatorial. 
4.6.4 Admissão do paciente no ambulatório de TCTH

Os pacientes que receberam alta da internação foram admitidos sob regime de Ambulatório para acompanhamento. Todos os pacientes que receberam alta da unidade de internação, bem como seus respectivos cuidadores foram recebidos no ambulatório do Serviço de TCTH, por enfermeiros especializados que orientaram acerca dos cuidados e alterações que inviabilizariam sua permanência em regime ambulatorial e também sobre a necessidade de comunicação/comparecimento em caso de anormalidades no período em que estão distantes do hospital. Ainda neste primeiro atendimento, além das orientações, os enfermeiros avaliaram os aspectos físicos, o cateter venoso central e coletaram toda informação possível sobre o paciente, identificando todos os focos que necessitavam de intervenção, seja da equipe de enfermagem, ou para discussão e atendimento de outro profissional da equipe multidisciplinar. Conforme protocolo do Serviço, neste primeiro atendimento, foram coletados: hemocultura, urocultura, protoparasitológico, hemograma e bioquímica.

A partir da admissão no ambulatório, os pacientes retornaram diariamente para receberem a terapia medicamentosa, transfusional, para a coleta de exames laboratoriais e avaliação multidisciplinar. Esta rotina manteve-se até a enxertia medular ou até que o paciente apresentasse condições de comparecer em dias intermitentes. No intuito de que os pacientes retornassem diariamente ao Ambulatório, as vagas na Casa de Apoio foram disponibilizadas para aqueles indivíduos residentes em outros Estados da Federação ou mesmo em regiões distantes do Serviço que inviabilizassem a logística de retornos diários. 
4.6.5 Aplasia e enxertia medular

A aplasia caracterizou-se pela diminuição da produção dos elementos sanguíneos da medula óssea, ocasionada pelas quimioterapias utilizadas no regime de condicionamento. $\mathrm{O}$ exame de hemograma dos pacientes foi coletado diariamente no ambulatório para acompanhamento da contagem das séries vermelha, branca e plaquetas. O período de neutropenia foi definido quando a contagem de leucócitos totais foi $<1000 / \mathrm{mm}^{3}$. O estímulo com G-CSF foi iniciado quando a contagem de leucócitos apresentava-se em redução $\left(<1000 / \mathrm{mm}^{3}\right)$ e cessado quando houve a enxertia medular.

O dia da enxertia medular foi considerado o primeiro de três dias consecutivos com contagem periférica de neutrófilos $\geq 500 / \mathrm{mm}^{3}$ (Weaver, 1997; Hansen et al., 1998).

O dia da enxertia plaquetária foi considerado o primeiro de sete dias consecutivos com contagem periférica de plaquetas $\geq 20.000 / \mathrm{mm}^{3}$, sem que tenha recebido transfusão (Weaver, 1997).

4.6.6 Hemoterapia - suporte transfusional pós TCTH

O exame de hemograma foi coletado diariamente desde o dia do TCTH até a enxertia medular e, após este período, conforme as necessidades transfusionais e clínicas. A transfusão de hemocomponentes no Ambulatório de TCTH seguiu o 
protocolo transfusional do Serviço. Os pacientes que apresentavam hemoglobina < $10 \mathrm{~g} / \mathrm{dL}$ receberam concentrado de hemácias irradiadas $(\mathrm{CHI})$ e aqueles em que a contagem de plaquetas foi $<20.000 / \mathrm{mm}^{3}$ receberam concentrado de plaquetas por aférese irradiadas (CPAI). Eventualmente, na falta de CPAI, foram transfundidos concentrados de plaquetas de doadores individuais. Todos os hemocomponentes administrados nos pacientes foram fornecidos pela Fundação Pró-Sangue Hemocentro de São Paulo e irradiados com 2500 cGy para reduzir o risco de Doença do Enxerto Contra o Hospedeiro (DECH), através da diminuição dos linfócitos T na bolsa (Anvisa, 2004).

\subsubsection{Profilaxias bacteriana, viral e fúngica}

Todos os pacientes foram submetidos a protocolos de profilaxias para infecções bacterianas, virais e fúngicas. A profilaxia bacteriana foi administrada desde o primeiro dia da neutropenia até a enxertia medular e consistiu na introdução de antibióticos por via intravenosa (IV) iniciando-se pela cefepima $2 \mathrm{~g}$ a cada 12 horas. Na ocorrência de hipertermia, caracterizada por temperatura axilar $\geq 37.8^{\circ} \mathrm{C}$ ou pela alteração clínica desfavorável, foi acrescentado a teicoplanina na dose de 400 mg a cada 24 horas. Em caso de hipertermia nas 24 horas subsequentes à introdução da teicoplanina foi introduzido o meropenem $2 \mathrm{~g}$ a cada 12 horas, suspenso a cefepima. Quando houve um novo episódio de hipertermia foi introduzido o colistimetato de sódio $150 \mathrm{mg}$ a cada 12 horas e se a temperatura corpórea se 
mantivesse elevada, levofloxacina $500 \mathrm{mg}$ a cada 24 horas, conforme protocolo do Serviço.

A profilaxia para vírus da família do Herpesviridae iniciou-se no dia do transplante e foi mantido até o D+30, utilizando aciclovir $250 \mathrm{mg}$ por via intravenosa a cada 12 horas até a enxertia medular e $200 \mathrm{mg}$ por via oral (VO) a cada 12 horas até completar 30 dias após o transplante.

O fluconazol foi administrado como profilaxia antifúngica durante o período de neutropenia. Nos pacientes com peso até $50 \mathrm{~kg}$ foi prescrita a dose de $200 \mathrm{mg}$ e nos pacientes que apresentavam peso $>50 \mathrm{~kg}$ a dose foi de $400 \mathrm{mg}$, ambas por via intravenosa e a cada 24 horas. Após a modificação e introdução da terapêutica citada, se o paciente ainda permanecesse febril, a Anfotericina B lipossomal seria introduzida empiricamente na dose de $3 \mathrm{mg} / \mathrm{kg} / \mathrm{dia}$.

4.6.8 Critérios de internação por intercorrências

Após o TCTHa, os pacientes que necessitaram de internação por intercorrências foram internados na Unidade de Internação do Instituto Central do Hospital das Clínicas (ICHC) após avaliação e decisão médica associados a um ou mais critérios:

1. Vômitos (grau 3);

2. Mucosite (grau 3);

3. Diarreia (grau 3); 
4. Dificuldade respiratória representada por sinais clínicos com ou sem presença de dessaturação de $\mathrm{O}_{2}$;

5. Hipertermia persistente mesmo em uso de antimicrobianos de amplo espectro;

6. Alteração com instabilidade hemodinâmica, clínica ou neurológica incompatível ao atendimento no ambulatório, diagnosticada após avaliação de sinais e sintomas clínicos e parâmetros vitais pela equipe médica;

7. Os critérios de um a três, de acordo com a avaliação e decisão médica.

4.6.9 Mucosite, náusea/ vômito e diarreia

A graduação da mucosite, náusea/vômito e diarreia foi aplicada de acordo com a escala descrita por Miller et al., 1981 e adaptada ao Serviço por Nicolau (2004a), conforme descrito na Tabela 2. 
Tabela 2 - Escala de avaliação de toxicidade ao regime de condicionamento

\begin{tabular}{|c|c|c|}
\hline Evento & Grau & Descrição \\
\hline \multirow{5}{*}{ Mucosite } & 0 & Ausente \\
\hline & 1 & Eritema discreto da mucosa oral, sem dor ao se alimentar. \\
\hline & 2 & $\begin{array}{l}\text { Eritema e ulceração da mucosa oral, necessitando de } \\
\text { tratamento analgésico, podendo deglutir sólidos. }\end{array}$ \\
\hline & 3 & $\begin{array}{l}\text { Ulceração da mucosa oral, necessitando de tratamento } \\
\text { analgésico e incapacidade de deglutir sólidos. }\end{array}$ \\
\hline & 4 & $\begin{array}{l}\text { Ulceração da mucosa oral, necessitando de tratamento } \\
\text { analgésico e incapacidade de deglutir quaisquer alimentos. }\end{array}$ \\
\hline \multirow{4}{*}{ Náusea/vômito } & 0 & Sem náusea ou vômito. \\
\hline & 1 & Náuseas ou até dois episódios de vômito por dia. \\
\hline & 2 & Náuseas e de dois a cinco episódios de vômito por dia. \\
\hline & 3 & $\begin{array}{l}\text { Náuseas persistentes e mais de cinco episódios de vômito } \\
\text { por dia. }\end{array}$ \\
\hline \multirow{4}{*}{ Diarreia } & 0 & Sem diarreia. \\
\hline & 1 & Até dois episódios de evacuações diarreicas ao dia. \\
\hline & 2 & De dois a cinco episódios de evacuações diarreicas ao dia. \\
\hline & 3 & mais do que cinco episódios diarreicas no dia. \\
\hline
\end{tabular}

\subsection{Análise estatística}

Para avaliação das variáveis analisadas foi empregada à técnica da estatística descritiva utilizando-se de números absolutos, médias e porcentagens da ocorrência de cada um dos desfechos propostos à análise. 
5. RESULTADOS 


\subsection{Características dos pacientes}

Dos cem pacientes inseridos neste estudo, $49 \%$ eram do sexo masculino e $51 \%$ do sexo feminino, havendo um pareamento não intencional quanto ao sexo. Em relação à cor da pele, indivíduos da cor branca prevaleceram (63\%) seguidos pela parda $(23 \%)$ e preta (14\%). A mediana de idade foi de 48,5 anos (19-69 anos).

Tabela 3 -Dados demográficos dos pacientes submetidos ao TCTHa (jan a dez 2009) Caracterização dos pacientes Número de pacientes no estudo (N=100)

Idade $\quad 48,5(19$ a 69 anos $)$

Sexo $\quad M=49(49 \%) \quad F=51(51 \%)$

\section{Branca $=63(63 \%)$}

Cor da pele

Parda $=23(23 \%)$

Preta $=14(14 \%)$

\subsection{Distribuição dos pacientes em relação à doença}

O diagnóstico dos cem pacientes estudados pode ser visto na Tabela 4. 
Tabela 4 - Distribuição dos pacientes de acordo com a doença

Diagnóstico

Número de pacientes

\begin{tabular}{lc}
\hline Mieloma Múltiplo & $45(45 \%)$ \\
Linfoma Não-Hodgkin & $25(25 \%)$ \\
Linfoma de Hodgkin & $21(21 \%)$ \\
Leucemia Mielóide Aguda & $9(9 \%)$ \\
TOTAL & $\mathbf{1 0 0 ( 1 0 0 \% )}$ \\
\hline
\end{tabular}

O subtipo das doenças dos pacientes, de acordo com as técnicas estabelecidas, foi observado na Tabela 5 .

Tabela 5 -Subtipo das doenças dos pacientes submetidos ao TCTHa (jan a dez 2009)

\begin{tabular}{lll}
\hline Doença & Subtipo & $\begin{array}{l}\text { Número de } \\
\text { pacientes (\%) }\end{array}$ \\
\hline & IgG & $22(22 \%)$ \\
Mieloma Múltiplo (MM) & IgA & $6(6 \%)$ \\
& Não secretor & $9(9 \%)$ \\
TOTAL & Não relatado & $8(8 \%)$ \\
& & $\mathbf{4 5}(\mathbf{4 5 \%})$ \\
Linfoma não-Hodgkin (LNH) & DGCB* & $16(16 \%)$ \\
& Manto & $5(5 \%)$ \\
TOTAL & Folicular & $2(2 \%)$ \\
Linfoma de Hodgkin (LH) & NK nasal** & $1(1 \%)$ \\
TOTAL & & $1(1 \%)$ \\
Leucemia Mielóide Aguda & Celularidade Mista & $\mathbf{2 5}(\mathbf{2 5 \%})$ \\
(LMA) & & $20(20 \%)$ \\
& M1 & $1(1 \%)$ \\
TOTAL & M4 & $4(4 \%)$ \\
\hline
\end{tabular}

Legenda: *DGCB= linfoma não-Hodgkin difuso de grandes células $\mathrm{B}$ $* * \mathrm{NK}=$ Natural Killer 


\subsection{Tratamento da doença de base previamente ao TCTH}

De acordo com a doença de base, os pacientes foram tratados previamente ao TCTHa com esquemas terapêuticos não quimioterápicos/radioterápicos ou esquemas quimioterápicos associados ou não à radioterapia. Quando foi avaliada a quantidade de esquemas terapêuticos pré-TCTH, notou-se que a mediana de protocolos utilizados foi de dois protocolos por paciente (variação: 1 a 4). Em relação ao tratamento não quimioterápico/radioterápico, os pacientes portadores de $\mathrm{MM}$ utilizaram drogas como a talidomida, dexametasona e em alguns casos ácido zoledrônico. Em 72 (72\%) pacientes foram utilizados tratamentos com quimioterápicos: os tipos de drogas mais utilizadas nos pacientes analisados foram os agentes alquilantes $(52 ; 72,2 \%)$, seguidos pelos análogos de platina $(13 ; 18 \%)$ e apenas um paciente fez uso de mitoxantrone $(1 ; 1,4 \%)$. A radioterapia foi utilizada no tratamento prévio à indicação de TCTH em 12 (12\%) pacientes. A Tabela 6 ilustra os protocolos terapêuticos pré-TCTH e o número de pacientes em que foram utilizados. 
Tabela 6 - Tratamento prévio à indicação do TCTH, de acordo com a doença

\begin{tabular}{lccccc}
\hline Diagnóstico & $\begin{array}{c}\text { Agentes } \\
\text { alquilantes }\end{array}$ & $\begin{array}{c}\text { Análogos da } \\
\text { platina }\end{array}$ & Mitoxantrone & Rt & Outros \\
\hline MM & 3 & 1 & 0 & 3 & 0 \\
LH & 21 & 7 & 1 & 2 & 0 \\
LNH & 25 & 5 & 0 & 7 & 0 \\
LMA & 3 & 0 & 0 & 0 & 6 \\
TOTAL & $\mathbf{5 2}$ & $\mathbf{1 3}$ & $\mathbf{1}$ & $\mathbf{1 2}$ & $\mathbf{6}$ \\
\hline
\end{tabular}

Legenda: $\mathrm{Rt}=$ radioterapia

Os agentes alquilantes foram os mais utilizados para o tratamento do LNH; os análogos de platina foram administrados em maior quantidade nos pacientes portadores de LH, embora a diferença seja insignificante se comparado ao seu uso nos pacientes com LNH. Apenas um paciente portador de $\mathrm{LH}$ foi tratado com o mitoxantrone e outros três pacientes portadores de LMA utilizaram estas classes de drogas em seus tratamentos prévios.

A Tabela 7 apresenta os dados referentes ao tipo de resposta da doença de base no momento do TCTH.

Tabela 7 - Tipo de resposta ao tratamento prévio ao TCTH de acordo com a doença

\begin{tabular}{lcccc}
\multicolumn{1}{c}{ Resposta } & Completa & Parcial & $\begin{array}{c}\text { Em recaída } \\
\text { extra-medular }\end{array}$ & TOTAL \\
\hline Mieloma Múltiplo & $17(37,8 \%)$ & $28(62,2 \%)$ & - & $45(100 \%)$ \\
Linfoma não-Hodgkin & $14(56 \%)$ & $8(32 \%)$ & $3(12 \%)$ & $25(100 \%)$ \\
Linfoma de Hodgkin & $5(23,8 \%)$ & $12(57,14 \%)$ & $4(19,05 \%)$ & $21(100 \%)$ \\
Leucemia Mielóide Aguda & $9(100 \%)$ & - & - & $9(100 \%)$ \\
TOTAL DE PACIENTES & $\mathbf{4 5}$ & $\mathbf{4 8}$ & $\mathbf{7}$ & $\mathbf{1 0 0 \%}$ \\
\hline
\end{tabular}




\subsection{Mobilização das CTH periféricas}

A mobilização das células-tronco hematopoiéticas periféricas foi realizada com ciclofosfamida $120 \mathrm{mg} / \mathrm{kg}$ de peso e G-CSF 10 a $20 \mathrm{mcg} / \mathrm{kg}$ de peso em $85(85 \%)$ pacientes. Foi utilizado apenas o G-CSF na mobilização de dez (10\%) pacientes, sendo oito portadores de mieloma múltiplo em resposta completa e dois de leucemia mielóide aguda. A ciclofosfamida $120 \mathrm{mgkg}$ de peso, gencitabina 2g/m² e G-CSF 10 a $20 \mathrm{mcg} k g$ de peso foi utilizada para cinco (5\%) pacientes, sendo três portadores de linfoma de Hodgkin e dois de linfoma não-Hodgkin. A Tabela 8 demonstra os resultados obtidos na mobilização das CTH.

Tabela 8 - Resultados da mobilização das CTH periféricas

\begin{tabular}{|c|c|}
\hline Mediana de células CD34+ periféricas (cél $\left./ \mathrm{mm}^{3}\right)$ & 23,75 \\
\hline Variação $\left(\right.$ cél $\left./ \mathbf{m m}^{3}\right)$ & $6,3-709,1$ \\
\hline Mediana de Dias de Mobilização & 13 \\
\hline Variação & $3-34$ \\
\hline Mediana de células CD34+ $\left(\times 1^{6}\right)$ coletadas & 4,74 \\
\hline Variação & $2,3-30,1$ \\
\hline
\end{tabular}

Todos os pacientes inseridos neste estudo coletaram as CTH por via intravenosa, através de um acesso venoso periférico calibroso ou um cateter venoso central, por procedimento de leucaférese até que fosse obtido o número de células CD34+ necessárias ao TCTH. A coleta das CTH foi realizada nos pacientes que apresentaram no primeiro dia da coleta, CD34+ periférico mediano de 23,75 
células $/ \mathrm{mm}^{3}$ (6,3-709,1 células $\left./ \mathrm{mm}^{3}\right)$. O período entre o início da mobilização até o início da(s) coleta(s) das CTH variou entre três a 34 dias, com mediana de 13 dias.

Em relação ao número de coletas em que o paciente foi submetido para a obtenção das CTH, 80 (80\%) pacientes foram submetidos a um procedimento, 17 (17\%) a dois procedimentos e três $(3 \%)$ pacientes a três procedimentos. Nesta casuística, cem (100\%) dos pacientes mobilizaram uma quantidade adequada de células para realização do TCTH.

Dentre os três pacientes que necessitaram de três coletas de CTH para atingir o número necessário de células para que fossem submetidos ao TCTHa:

- Dois pacientes eram portadores de LH e um de LNH;

- Todos coletaram células CD34+> 3,0 x $10^{6} / \mathrm{kg}$ de peso;

- Os pacientes portadores de LH apresentavam idade $<35$ anos e estavam em resposta parcial ao tratamento prévio ao TCTHa. O paciente portador de $\mathrm{LNH}$ tinha 60 anos e era refratário ao tratamento anterior ao TCTHa.

\subsection{Regimes de condicionamento para o TCTHa}

Os regimes de condicionamento com altas doses de quimioterapia basearamse nos protocolos do Serviço e estão representados na Tabela 9. 
Tabela 9 - Regimes de condicionamento utilizados de acordo com a doença

\begin{tabular}{lcc}
\hline Tipo de condicionamento & Doença & Número de pacientes \\
\hline BU12+MEL100 & MM & 40 \\
MEL 200 & MM & 2 \\
BEAM 400 & LNH & 16 \\
BEAM 400 & LH & 20 \\
BEAM & LNH & 9 \\
BEAM & LH & 1 \\
BU16/MEL140 & LMA & 8 \\
OUTROS: & & 1 \\
\multicolumn{1}{c}{ BU8+MEL70 } & LMA & 3 \\
\hline \multicolumn{1}{c}{ BU6+MEL50 } & MM & \\
\hline
\end{tabular}

Legenda: $\mathrm{BEAM}$ = carmustina, etoposide, citarabina e melfalano; $\mathrm{BU}=$ busulfano; $\mathrm{MEL}=$ melfalano.

Quatro dos pacientes tiveram as doses das quimioterapias ajustadas à condição clínica (de acordo com a avaliação clínica e índice de Karnofsky) e pela constatação da fração de ejeção de ventrículo esquerdo (FEVE) diminuída.

5.5.1 Toxicidades ao regime de condicionamento

As toxicidades relacionadas ao regime de condicionamento foram graduadas através da escala de toxicidade da Organização Mundial de Saúde (OMS) (Miller et al.,1981) adaptada ao Serviço por Nicolau (2004a). A Tabela 10 ilustra a porcentagem de pacientes que apresentaram toxicidades na amostra estudada. 
Tabela 10 - Graduação das toxicidades após regime de condicionamento

Pacientes (N=100)

\begin{tabular}{rcc}
\hline Mucosite & Grau 0 & $31(31 \%)$ \\
Grau 1 a 2 & $58(58 \%)$ \\
Grau 3 a 4 & $11(11 \%)$ \\
\hline Náusea/vômito & \\
\hline Grau 0 & $16(16 \%)$ \\
Grau 1 & $62(62 \%)$ \\
Grau 2 & $14(14 \%)$ \\
Grau 3 & $8(8 \%)$ \\
Diarreia & Grau 0 & $25(25 \%)$ \\
Grau 1 & $14(14 \%)$ \\
Grau 2 & $31(31 \%)$ \\
Grau 3 & $30(30 \%)$ \\
\hline
\end{tabular}

5.5.2 Toxicidades relacionadas ao regime de condicionamento BEAM 400

Dos cem (100\%) pacientes que totalizam a amostra estudada, 36 (36\%) pacientes foram submetidos ao regime de condicionamento BEAM 400. As graduações das toxicidades relacionadas ao regime de condicionamento estão dispostas na Tabela 11. 
Tabela 11 - Graduação das toxicidades relacionadas ao regime de condicionamento BEAM 400

\begin{tabular}{ll}
\hline Tipo de toxicidade & Número de pacientes \\
\hline \multirow{3}{*}{ Mucosite } & Grau $0=13$ \\
& Grau 1 a $2=21$ \\
& Grau $3=2$ \\
& TOTAL: 36 pacientes \\
& Grau $0=7$ \\
& Grau $1=16$ \\
Náusea/vômitos & Grau $2=8$ \\
& Grau 3=5 \\
& TOTAL: $\mathbf{3 6}$ pacientes \\
& Grau $0=5$ \\
& Grau $1=2$ \\
Diarréia & Grau 2=12 \\
& Grau 3=15 \\
& Grau 4=2 \\
& TOTAL: $\mathbf{3 6}$ pacientes \\
\hline
\end{tabular}

Nesta amostra foram observados 9/36 (25\%) episódios de internação, decorrentes da toxicidade do regime de condicionamento. A diarreia grau 2 e 3 foi a toxicidade mais frequente em 27/36 (75\%) pacientes.

5.5.3 Toxicidades relacionadas ao regime de condicionamento BEAM

Quando analisada a incidência das toxicidades relacionadas ao regime de condicionamento BEAM, observamos que dos dez (10\%) pacientes que receberam este condicionamento, quatro (40\%) apresentaram mucosite nos graus 1 a 2 . Ainda, a incidência de náusea/vômitos grau 1 foi de nove (90\%) pacientes. A incidência de 
diarreia foi observada em sete pacientes $(70 \%)$, sendo três pacientes grau 1 , um paciente grau 2, três pacientes grau 3. Nesta amostra foi observada uma internação hospitalar decorrente da toxicidade ao regime de condicionamento.

5.5.4 Toxicidades relacionadas ao regime de condicionamento BU12/MEL100

As toxicidades ao regime de condicionamento BU 12/MEL 100, aos quais 40 pacientes (40\%) foram submetidos estão dispostas na tabela 12.

Tabela 12 - Graduação das toxicidades relacionadas ao regime de condicionamento BU 12/MEL 100

\begin{tabular}{ll}
\hline Toxicidade & Graduação \\
\hline \multirow{3}{*}{ Náusea/vômito } & Grau $0=7$ \\
& Grau $1=25$ \\
& Grau 2 $=6$ \\
& Grau 3=2 \\
& TOTAL: 40 pacientes \\
& Grau $0=10$ \\
Mucosite & Grau 1 a 2=25 \\
& Grau 3=4 \\
& Grau 4=1 \\
& TOTAL: 40 pacientes \\
Diarréia & Grau $0=14$ \\
& Grau 1=4 \\
& Grau 2=13 \\
& Grau 3=9 \\
& TOTAL: 40 pacientes \\
\hline
\end{tabular}


Nesta amostra a náusea/vômito grau 1 foi observada em 25/40 (62,5\%) pacientes, a mucosite grau 1 a 2 25/40 (62,5\%) dos pacientes, a diarreia grau 2, em 13/40 (32,5\%) pacientes. Apenas um paciente necessitou de internação em decorrência da toxicidade ao regime de condicionamento, mais especificamente, por mucosite grau 4.

5.5.5 Toxicidades relacionadas ao regime de condicionamento MEL 200

Apenas dois pacientes foram submetidos ao regime de condicionamento MEL 200, destes, apenas um paciente apresentou mucosite grau 1. A incidência de náusea/vômitos grau 2 e a diarreia, foram observadas nos dois pacientes, sendo um paciente grau 1 e um paciente grau 2. Não houve internação hospitalar relacionada ao regime de condicionamento MEL 200.

5.5.6 Toxicidades relacionadas ao regime de condicionamento BU16/MEL140

Quando analisada a incidência das toxicidades nesta amostra de pacientes $(\mathrm{N}=8)$, observamos que sete $(7 / 8 ; 87,5 \%)$ pacientes apresentaram mucosite, sendo que cinco $(5 / 7 ; 71,4 \%)$ destes, nos graus 1 e 2 , um $(1 / 7 ; 14,3 \%)$ paciente apresentou grau 3 e um $(1 / 7 ; 14,3 \%)$ paciente grau 4 . Ainda, a incidência de náusea/vômitos foi 
de seis $(6 / 8 ; 75 \%)$ pacientes, sendo quatro $(4 / 6 ; 66,7 \%)$ pacientes grau I, um $(1 / 6$; $16,7 \%$ ) paciente grau 2 e um paciente grau 3. A incidência de diarreia foi observada em cinco $(5 / 7 ; 71,4 \%)$ pacientes, sendo um $(1 / 5 ; 20 \%)$ paciente grau 1 , dois $(2 / 5$; $40 \%$ ) pacientes grau 2 , dois $(2 / 5 ; 40 \%)$ pacientes grau 3. Nesta amostra foi observado um episódio de internação por síndrome obstrutiva sinusoidal (SOS).

\subsubsection{Outros regimes de condicionamento com dose reduzida}

Outros regimes de condicionamento $(\mathrm{N}=4)$ apresentaram três $(3 / 4 ; 75 \%)$ pacientes com mucosite, sendo dois $(2 / 3 ; 66,7 \%)$ nos graus 1 a 2 e um $(1 / 3 ; 33,3 \%)$ paciente grau 3. Ainda, a incidência de náusea/vômitos foi de três $(3 / 4 ; 75 \%)$ pacientes, sendo dois $(2 / 3 ; 66,7 \%)$ pacientes grau 1 e um paciente grau $3(1 / 3$; 33,3\%). A incidência de diarreia foi observada nos quatro (100\%) pacientes, sendo dois $(2 / 4 ; 50 \%)$ pacientes grau 1 e dois $(2 / 4 ; 50 \%)$ pacientes grau 2.

\subsection{Alta hospitalar precoce pós-TCTH}

A alta hospitalar foi definida como a alta que ocorreu nos primeiros dez dias após o TCTH e está representada na Tabela 13. 
Tabela 13 - Alta hospitalar precoce até o D+10

Dia pós-TCTH na alta hospitalar Número de pacientes

\begin{tabular}{cc}
\hline D+1 & $59(59 \%)$ \\
$\mathbf{D}+\mathbf{2}$ & $18(18 \%)$ \\
$\mathbf{D}+\mathbf{3}$ & $9(9 \%)$ \\
$\mathbf{D}+\mathbf{4}$ & $6(6 \%)$ \\
$\mathbf{D}+\mathbf{5}$ & $2(2 \%)$ \\
$\mathbf{D + 6}$ & $4(4 \%)$ \\
D+9 & $2(2 \%)$ \\
TOTAL & $\mathbf{1 0 0}(\mathbf{1 0 0 \%})$ \\
\hline
\end{tabular}

Em relação à alta hospitalar precoce, nenhum paciente desta amostra, nos dias sete, oito e dez pós-TCTH recebeu alta. Os pacientes receberam a continuidade de seus tratamentos após a alta hospitalar precoce, no ambulatório, comparecendo diariamente para monitorização dos exames laboratoriais, acompanhamento clínico, transfusões de hemocomponentes e administração de medicamentos, curativos ou qualquer outra atividade associada ao seu tratamento.

5.6.1 Local de estadia dos pacientes na fase ambulatorial após alta hospitalar precoce

Após a alta hospitalar, os pacientes foram encaminhados para estadias em residências próprias, de membros da família ou de conhecidos. Os pacientes que não possuíam familiares e/ou conhecidos na cidade de São Paulo foram encaminhados 
para estadia na Casa de Apoio. A Tabela 14 mostra o tipo de estadia e o número de pacientes para cada uma delas.

Tabela 14 - Tipo de estadia após alta hospitalar da unidade de internação

\begin{tabular}{lc}
\hline Tipo de estadia & Número de pacientes \\
\hline Residencial & $54(54 \%)$ \\
Casa de Apoio & $46(46 \%)$ \\
TOTAL & $\mathbf{1 0 0 ( 1 0 0 \% )}$ \\
\hline
\end{tabular}

No período de acompanhamento ambulatorial, o paciente e cuidador poderiam optar por manter-se em ambiente residencial (própria residência, de familiares, etc.) independente da distância ou teriam a possibilidade de estadia na Casa de Apoio, pelo tempo em que fosse necessário. A decisão foi mediada por um profissional seguindo os critérios mínimos necessários ao paciente transplantado, uma vez que não há visita domiciliar. Ao paciente foi exigido um acompanhante que estivesse disponível diariamente e permanesse durante todo o período em que o paciente estivesse em atendimento no ambulatório.

\subsection{Enxertia dos granulócitos e plaquetas}

O período entre a infusão das $\mathrm{CTH}$ e enxertia dos granulócitos apresentou mediana de 12 dias (variação: 10 a 34 dias) e a enxertia de plaquetas apresentou 
mediana de 15 dias (variação: 7 a 526 dias). A Tabela 15 apresenta os resultados da enxertia dos granulócitos e das plaquetas. Não foi possível avaliar a enxertia das plaquetas em nove pacientes, dois pacientes evoluíram para óbito antes da enxertia medular e sete pacientes receberam alta para retornarem ao Serviço de origem.

Tabela 15 - Enxertia de granulócitos e plaquetas

Mediana da Enxertia de Granulócitos (em dias) 12 Variação (dias) $10-34$

Enxertia de Plaquetas $(\mathrm{N}=100)$

$\operatorname{Sim}(\%)$

Não $(\%)$

Mediana da Enxertia de Plaquetas (em dias)

Variação (dias)

Os pacientes receberam uma mediana de três unidades de concentrados de hemácias e quatro unidades de concentrados de plaquetas por aférese desde o TCTH até a alta do Serviço. A Tabela 16 apresenta a variação e a mediana de transfusões de hemocomponentes do TCTH até a alta do Serviço nos cem pacientes analisados. 
Tabela 16 - Variação e mediana de transfusão de concentrado de hemácias e plaquetas do TCTHa até a alta do serviço $(\mathrm{N}=100)$

\begin{tabular}{ll}
\hline Mediana de Concentrado de Hemácias (unidade) & 3
\end{tabular}

\begin{tabular}{lc}
\hline Variação & $0-53$
\end{tabular}

Mediana de Concentrado de Plaquetas (unidade) 4

Variação $1-165$

\subsection{Internação dos pacientes após alta hospitalar precoce}

Dos cem pacientes analisados, vinte e três pacientes (23\%) necessitaram de internação pós-TCTH. Destes pacientes, 19/23 (82,6\%) foram internados uma vez; três $(3 / 23 ; 13,04 \%)$ necessitaram de internação por duas vezes e um $(1 / 23 ; 4,4 \%)$ paciente por três vezes, totalizando 28 internações (conforme tabela 17).

Tabela 17 - Frequência de internação hospitalar após alta hospitalar precoce

Frequência de internação Número de pacientes

\begin{tabular}{lc}
\hline Uma internação & 19
\end{tabular}

Duas internações

3

Três internações

Das 28 internações analisadas, 19/28 (67,9\%) foram necessárias no período de aplasia, sendo que dez $(10 / 28 ; 35,71 \%)$ internações estavam relacionadas à 
toxicidade ao regime de condicionamento e apresentaram como principal sintomatologia a gastrointestinal. As demais causas de internação foram: a infecção $(4 / 28 ; 14,28 \%)$, alterações respiratórias ou pulmonares $(3 / 28 ; 10,71 \%)$, SOS $(2 / 28$; $7,14 \%)$, hipotensão arterial $(2 / 28 ; 7,14 \%), \operatorname{HDA}(2 / 28 ; 7,14 \%)$, hematúria $(2 / 28$; $7,14 \%)$, bacteremia $(1 / 28 ; 3,57 \%)$, bradicardia $(1 / 28 ; 3,57 \%)$ e taquicardia $(1 / 28$; 3,57\%). A Tabela 18 ilustra as principais causas das internações.

Tabela 18 - Etiologia das internações pós -TCTH com alta hospitalar precoce Etiologia Número de internações

\begin{tabular}{lc}
\hline Toxicidade ao Condicionamento & 10 \\
Infecção & 4 \\
Alterações Respiratórias ou Pulmonares & 3 \\
SOS & 2 \\
Hipotensão Arterial & 2 \\
HAD & 2 \\
Hematúria & 2 \\
Bacteremia & 1 \\
Bradicardia & 1 \\
Taquicardia & 1 \\
TOTAL & $\mathbf{2 8}$ \\
\hline
\end{tabular}

Legenda: $\mathrm{SOS}=$ síndrome obstrutiva sinusoidal; $\mathrm{HDA}=$ hemorragia digestória alta. 


\subsection{Ocorrência de infecção pós-TCTH}

As ocorrências de infecções foram avaliadas desde a admissão do paciente no ambulatório, após a alta da unidade de internação e até o D+30. Os pacientes permaneceram hospitalizados no período entre o regime de condicionamento até a infusão das CTH. Aqueles que estavam em condições receberam alta hospitalar, dando continuidade ao tratamento em nível ambulatorial.

No ambulatório, alguns protocolos foram seguidos desde a admissão do paciente, onde foram coletadas amostras de hemocultura e urocultura com o objetivo de identificar precocemente algum micro-organismo. Caso a cultura apresentasse resultado positivo, o paciente seria tratado. A neutropenia febril esteve presente em $58(58 \%)$ dos pacientes até a enxertia medular. Sendo assim, dos cem pacientes analisados, 11 pacientes apresentaram culturas positivas até o trigésimo dia pósTCTH e sete pacientes $(7 / 11 ; 63,6 \%)$, presença de micro-organismos no período da aplasia medular (seis hemoculturas e uma urocultura); um paciente apresentou hemocultura com presença de dois micro-organismos. Todos os pacientes foram tratados com antimicrobianos adequados, segundo antibiograma.

A Tabela 19 apresenta os resultados das culturas positivas desde a alta hospitalar até o D+30. 
Tabela 19 - Micro-organismos presentes nas culturas dos pacientes até D+30

\begin{tabular}{|c|c|c|c|c|c|c|c|}
\hline Id. & Doença & Idade & Cond. & $\begin{array}{c}\text { Sinais/ } \\
\text { Sintomas }\end{array}$ & D+ & Cultura & $\begin{array}{c}\text { Micro- } \\
\text { organismo }\end{array}$ \\
\hline $1834^{*}$ & MM & 69 & $\begin{array}{c}\text { Bu12/ } \\
\text { Mel100 }\end{array}$ & Febre & +15 & URO & Escherichia coli \\
\hline 1758 & LH & 33 & Beam 400 & Bacteremia & +21 & HMC & $\begin{array}{c}\text { Enterobacter } \\
\text { cloacae }\end{array}$ \\
\hline 1761 & LH & 21 & Beam 400 & Febre & +16 & HMC & $\begin{array}{c}\text { Klebsiela } \\
\text { pneumoniae }\end{array}$ \\
\hline 1765 & LNH & 33 & Beam 400 & Febre & +13 & HMC & Lactobacilus sp \\
\hline 1859 & LNH & 32 & Beam 400 & Febre & +22 & $\mathrm{HMC}$ & $\begin{array}{c}\text { Staphylococcus } \\
\text { coagulase } \\
\text { negativo } \mathrm{e} \\
\text { Citrobacter } \\
\text { freundii complex }\end{array}$ \\
\hline $1827^{*}$ & $\mathrm{LH}$ & 51 & Beam & Febre & +7 & HMC & $\begin{array}{c}\text { Enterococcus } \\
\text { faecium }\end{array}$ \\
\hline $1840^{*}$ & MM & 67 & Bu6/Mel50 & Febre & +10 & $\mathrm{HMC}$ & $\begin{array}{c}\text { Staphylococcus } \\
\text { coagulase } \\
\text { negativo }\end{array}$ \\
\hline $1868^{*}$ & MM & 28 & $\begin{array}{l}\text { Bu 12/ } \\
\text { Mel100 }\end{array}$ & Bacteremia & +8 & HMC & $\begin{array}{c}\text { Candica albicans } \\
\text { e Enterococcus } \\
\text { faecium }\end{array}$ \\
\hline $1831^{*}$ & LH & 27 & Beam 400 & Bacteremia & +8 & HMC & $\begin{array}{l}\text { Enterococcus } \\
\text { faecium }\end{array}$ \\
\hline $1893^{*}$ & $\mathrm{LH}$ & 57 & Beam 400 & Febre & +6 & HMC & $\begin{array}{l}\text { Enterococcus } \\
\text { faecalis }\end{array}$ \\
\hline $1855^{*}$ & MM & 56 & $\begin{array}{c}\text { Bu 12/ } \\
\text { Mel } 100\end{array}$ & Febre & +20 & $\mathrm{HMC}$ & $\begin{array}{l}\text { Stahylococcus } \\
\text { coagulase } \\
\text { negativo }\end{array}$ \\
\hline
\end{tabular}

Legenda: Id: identificação do paciente; Cond: regime de condicionamento utilizado; D+: dias pós TCTH; *ocorrido durante a fase de aplasia.

A Tabela 20 demonstra a classificação dos micro-organismos e sítios de coleta de culturas até $\mathrm{D}+30$. 
Tabela 20 - Classificação dos micro-organismos e sítios de coleta das culturas até o $\mathrm{D}+30$

\begin{tabular}{lccc}
\hline & Gram+ & Gram- & Fungos \\
\hline Hemocultura & 6 & 3 & 1 \\
Urocultura & zero & 1 & 1 \\
TOTAL & $\mathbf{6}$ & $\mathbf{4}$ & $\mathbf{2}$ \\
\hline
\end{tabular}

Legenda: Gram+: bactéria gram positiva; Gram-: bactéria gram negativa.

A Tabela 21 mostra os principais micro-organismos encontrados nas culturas coletadas até o D+30.

Tabela 21 - Micro-organismos encontrados nas culturas até o D+30

\begin{tabular}{lc}
\hline \multicolumn{1}{c}{ Micro-organismos } & Culturas positivas \\
\hline Staphylococcus coagulase negativo & 3 \\
Enterococcus faecium & 2 \\
Enterococcus faecalis & 1 \\
Lactobacillus SP & 1 \\
Escherichia coli & 1 \\
Enterobacter cloacae & 1 \\
Klebsiella pneumoniae & 1 \\
Citrobacter freundii & 1 \\
Candida albicans & 1 \\
TOTAL & $\mathbf{1 2}$ \\
\hline
\end{tabular}

Os 12 pacientes com infecções documentadas apresentaram hipertermia $\left(\mathrm{T} \geq 37,8^{\circ} \mathrm{C}\right)$, porém três pacientes $(3 / 14 ; 21,4 \%)$ apresentaram bacteremia. 


\subsection{Mortalidade até 100 dias pós-TCTHa}

No período analisado, quatro pacientes evoluíram para óbito até 100 dias pósTCTH, dois por choque séptico ( $\mathrm{D}+13 \mathrm{e} \cong 3$ meses), um por pneumonia viral $(+57)$ e um por recidiva da doença ( $\cong 3$ meses). Vale resaltar que dois pacientes, já haviam recebido alta do Serviço, dando continuidade ao tratamento no Serviço de origem. A Tabela 22 ilustra a causa de óbito o tempo pós-TCTH dos pacientes que evoluíram para óbito.

Tabela 22 - Diagnóstico, etiologia e tempo após o TCTHa dos pacientes que evoluíram para óbito em até 100 dias

\begin{tabular}{c|c|c|c}
\hline ID. do Paciente & Diagnóstico & Causa do óbito & $\begin{array}{c}\text { Tempo pós-TCTH } \\
\text { no óbito }\end{array}$ \\
\hline 1816 & LH & Choque séptico & +13 \\
\hline 1878 & LNH & Pneumonia & +57 \\
\hline 1830 & LH & Recidiva da doença & $\cong 90$ dias \\
\hline 1903 & LNH & Choque séptico & $\cong 90$ dias \\
\hline
\end{tabular}




\subsection{Tempo de permanência no Serviço pós-TCTHa}

O tempo de permanência dos pacientes no Serviço foi o período compreendido entre o dia do TCTH até a alta para retorno ao médico de origem de cada paciente. Os pacientes permaneceram no Serviço em uma mediana de 55 dias. A Tabela 23 demonstra o tempo de permanência do paciente no ambulatório até que retornassem para seguimento no seu Serviço de origem. A alta do Serviço apresentou uma ampla variação de dias, desde 26 dias, até um paciente que permanece em atendimento no ambulatório. A alta do Serviço mais precoce foi dada aos pacientes transplantados por MM, variando de 26 a 114 dias (mediana: 50 dias).

Tabela 23 - Tempo de permanência no Serviço de TCTH até a alta do paciente

\begin{tabular}{c|c|c}
\hline \multirow{2}{*}{$\begin{array}{c}\text { Tempo de permanência } \\
\text { Doença }\end{array}$} & $\begin{array}{c}\text { Mediana de } \\
\text { Permanência (dias) }\end{array}$ & Variação \\
\cline { 2 - 3 } & 55 & $13-325$ \\
\hline MM & 50 & $26-221$ \\
\hline LH & 81 & $13-250$ \\
\hline LNH & 56,5 & $28-325$ \\
\hline LMA & 55 & $39-153$ \\
\hline
\end{tabular}


6. DISCUSSÃO 
O Serviço de TCTH do HC-FMUSP é um Centro transplantador pioneiro na modalidade alta hospitalar precoce e praticamente o único no Brasil a utilizar-se deste tratamento de maneira rotineira. Esta análise retrospectiva foi realizada com a casuística de um único Centro transplantador e de forma consecutiva. Os dados avaliados puderam responder as perguntas que foram feitas em relação à segurança e factibilidade da modalidade de TCTHa com alta hospitalar precoce.

O TCTHa com alta hospitalar precoce é um tratamento utilizado mundialmente, na maioria dos Centros, com técnicas e protocolos semelhantes, porém deve-se enfatizar que cada país tem sua cultura, suas condições socioeconômicas, seu contexto de preparo e importância ao profissional e também que alguns aspectos, como o enfrentamento da doença e tratamento por parte dos pacientes e seus familiares podem influenciar no desfecho do procedimento.

A alta hospitalar precoce permite que haja uma agilidade no número de pacientes atendidos, reduzindo assim, o tempo entre o diagnóstico e/ou indicação e a realização do transplante. A diminuição dos dias de internação dos pacientes portadores de doenças hematológicas e o tratamento ambulatorial destes pacientes tem sido uma tendência nos últimos anos (Mank et al., 2010b). Segundo a experiência, este fato deve ser considerado dado à urgência do tratamento para algumas doenças, o que levaria a um benefício evidente ao paciente.

Em um contexto global, a equipe de enfermagem tem atuação importante nos cuidados aos pacientes submetidos ao TCTH, pois independente da fase do tratamento que estão, necessitam estabelecer vínculos de comunicação e confiança através de um eficaz relacionamento interpessoal tanto com o paciente, quanto com o familiar e/ou cuidador. Através dessa comunicação é que o profissional poderá 
ajudar o paciente a conceituar seus problemas, enfrentá-los, visualizar sua participação na experiência e alternativa de solução dos mesmos, além de encontrar novos padrões de comportamento (Veiga et al., 2010).

Entre os membros da equipe de enfermagem, deve ser uma constante a prestação de assistência que assegure a qualidade e segurança; estabelecer comunicação, fornecendo orientações adequadas e precisas; identificar e intervir precocemente os sinais e sintomas; estabelecer medidas de conforto; aprimorar conhecimentos e desenvolver planos de cuidados efetivos.

Ao analisar os dados obtidos neste estudo verificamos que a modalidade alta hospitalar precoce é viável para o atendimento ambulatorial, por apresentar resultados semelhantes à literatura e aos resultados de estudos realizados neste Serviço. Vale ressaltar, que o sucesso desta modalidade de TCTH depende de uma estrutura de atendimento que contemple planejamento do cuidado, estrutura de serviços e acessibilidade, com o objetivo de assistir ao paciente prontamente, identificando alterações que não possam ser assistidas no ambulatório, seja pela complexidade da complicação ou pelo horário de funcionamento. O ideal é que o paciente seja tratado como em uma unidade de internação, porém com melhores resultados que justifiquem a sua permanência no ambulatório.

A proposta de analisar alguns aspectos da mobilização paralelamente aos resultados do TCTH permitiu que verificássemos se havia alguma relação entre as fases do pré e do pós-TCTH estabelecendo, caso houvesse, uma relação entre os resultados da mobilização e do TCTH com alta hospitalar precoce. E ainda, a partir dos resultados, verificar as possíveis implicações para a enfermagem. 
Nos últimos anos, a diminuição no período de internação dos pacientes portadores de doenças hematológicas passou a ser uma tendência devido às facilidades do tratamento em regime ambulatorial (Mank et al., 2010b). A alta hospitalar precoce também abrange a população de pacientes idosos, embora muitos pacientes potencialmente candidatos ainda não podem ter acesso a esta opção de tratamento devido às limitações ocasionadas por outras morbidades que influenciam o resultado, como função renal prejudicada e o comprometimento das CTH pelo uso prolongado de agentes alquilantes (Jagannath et al., 1997; Murphy et al., 2009;).

Segundo os dados do Center for International Blood and Marrow Transplant Registry (CIBMTR), para o ano de 2009, a indicação aproximada de TCTH foi de 4700 pacientes portadores de MM, 3700 linfomas e 250 pacientes com LMA. No nosso estudo, a amostra analisada foi de 45 (45\%) pacientes portadores de MM, 46 (46\%) portadores de linfomas e nove (9\%) portadores de LMA, em concordância com a estimativa do CIBMTR (2009).

Antes do TCTH os pacientes são submetidos a esquemas de tratamento com o objetivo de estabilizar a doença de base, compostos por agentes quimioterápicos citotóxicos. Quanto ao tratamento com quimioterapia e/ou radioterapia, prévios ao TCTHa, a mediana de protocolos utilizados para esta casuística no tratamento da doença foi de dois protocolos por paciente, variando de um a quatro protocolos.

Alguns fatores como a idade, o tipo e a dose do fator de crescimento (dose única diária ou fracionada) e da quimioterapia/radioterapia aos quais os pacientes foram submetidos previamente podem interferir na mobilização das CTH (Mendrone et al., 2008b; Özkurt et al., 2010; Rosenbeck et al., 2010; Malik et al., 2011). É sabido que os pacientes que fazem uso de agentes alquilantes nos esquemas de 
tratamento da doença previamente ao TCTHa podem apresentar maiores dificuldades e até insucesso na mobilização (Rosenbeck et al., 2010). Na amostra estudada, $72 \%$ dos pacientes submetidos ao TCTHa foram tratados com um a quatro protocolos que incluíram quimioterapia e/ou radioterapia antes do transplante, porém os tratamentos com quimioterapia e radioterapia não interferiram no sucesso das coletas, visto que 100\% dos pacientes obtiveram um número suficiente de células para a realização do TCTHa.

Embora ainda não estejam bem definidos os critérios que caracterizam o insucesso na mobilização, considera-se um mau mobilizador os pacientes que recebem G-CSF precedido ou não por quimioterapia e que não atinjam um número de CTH suficiente para realização do transplante (Kuittinen et al., 2004; Wuchter et al., 2010). O número de procedimentos necessários para a coleta das CTH é determinado pela eficiência do regime de mobilização (Mohty; Ho, 2011).

O regime de mobilização pode ser realizado apenas com drogas quimioterápicas ou fatores de crescimento (G-CSF) ou através da combinação de ambos (Özkurt et al., 2010). A associação entre quimioterápicos e fatores de crescimento aumenta a quantidade de células CD34+ circulantes em até 60 vezes, sendo a ciclofosfamida a droga citotóxica mais utilizada para mobilizar as $\mathrm{CTH}$, em doses variadas, de acordo com a doença e resposta ao tratamento (Arslan; Moog, 2007; Toreend et al., 2007; Jagasia et al., 2011; Sheppard et al., 2012). O uso apenas de fatores de crescimento pode aumentar em até 18 vezes o número de CTH circulante (Toreend et al., 2007). Nesta amostra, a mobilização foi realizada com quimioterapia e G-CSF (90\%) e apenas G-CSF (10\%). O estímulo com G-CSF pode provocar alguns efeitos adversos bem tolerados pelos pacientes, incluindo dor óssea, mialgias, febre, cefaleia e náusea. 
Raramente ocorrem complicações secundárias ao uso de G-CSF, como a ruptura esplênica e a síndrome da angústia respiratória (Arslan; Moog, 2007; Rosenbeck et al., 2010). Na fase de mobilização, a equipe de enfermagem deve traçar um plano de cuidados preventivos e de intervenções, a partir de sua experiência e conhecimento científico acerca dos possíveis sinais e efeitos como dor, analgesia, medicações administradas e efeitos adversos, hipertermia, náusea, vômito e sangramento. Os cuidados de enfermagem também devem contemplar a segurança do paciente, orientação sobre os efeitos colaterais, higiene, limpeza, alimentação e cuidados com o cateter venoso central (CVC). O cuidado com o cateter venoso central deve ser meticuloso na tentativa de impedir a infecção e a obstrução dos lúmens, o que inviabilizaria a coleta das CTH. Ainda sobre o CVC, o óstio de inserção dos cateteres na pele, deve ser avaliado diariamente e os lúmens, heparinizados conforme protocolo institucional. Na casuística estudada, independente do tipo de regime de mobilização empregado, não houve insucesso na coleta das CTH.

A coleta das CTH periféricas é um procedimento adotado desde 1980 sendo uma alternativa viável na maioria das doenças hematológicas e utilizado devido às suas vantagens, principalmente pela possibilidade de enxertia mais rápida (Wuchter et al., 2010). Cerca de $80 \%$ dos pacientes houve a necessidade de apenas um procedimento de coleta para atingir uma quantidade segura de CTH para a realização do transplante, outros 17 pacientes necessitaram de duas coletas e três pacientes, de três coletas. Como produto das coletas, espera-se que seja atingido o número mínimo de células para realizar o TCTH. Consensualmente, a quantidade de 2 x $10^{6}$ células CD34+/kg de peso é um valor seguro para a enxertia adequada dos neutrófilos e plaquetas em aproximadamente 14 dias após o TCTH (Rosenbeck et al., 2010). 
Alguns Centros transplantadores consideram que 5,0 x $10^{6}$ células CD34+/kg de peso seria o valor ideal, pois diminui o tempo de recuperação hematológica e custos (Arslan; Moog, 2007; Mendrone, 2007a; Jagasia et al., 2011). No nosso estudo, os resultados foram bastante condizentes com a literatura consultada, onde a mediana de células CD34+ proveniente das coletas dos pacientes foi de $4,74 \times 10^{6} / \mathrm{kg}$ de peso, a mediana da enxertia dos neutrófilos aconteceu em 12 dias e a mediana das plaquetas em 15 dias.

Watts et al (1997) estudou a relação entre o número de CTH coletadas e a recuperação hematológica pós-TCTH em 101 pacientes portadores de linfoma e que foram mobilizados com ciclofosfamida e G-CSF. Foi observado que o número de células de $1,0 \times 10^{6} / \mathrm{kg}$ de peso era adequado para a enxertia dos neutrófilos e plaquetas na maioria dos pacientes, mas que o número de células de $3,5 \times 10^{6} / \mathrm{kg}$ de peso otimizava a enxertia de plaquetas. Valores acima de $3,5 \times 10^{6} / \mathrm{kg}$ de peso, faziam com que a enxertia das plaquetas fosse rara em um período acima de 28 dias. Neste estudo, 19 pacientes portadores de linfoma, sendo sete em resposta completa (RC), nove em resposta parcial (RP) e três refratários, mobilizados com ciclofosfamida e G-CSF coletaram um número de $\mathrm{CTH}<3,5 \times 10^{6} / \mathrm{kg}$ de peso, sendo que destes, $7 / 19(36,85 \%)$ tiveram a enxertia de plaquetas acima de 28 dias.

No contexto deste processo, a equipe de enfermagem tem como responsabilidade a verificação precisa do peso e altura do paciente, a orientação sobre o procedimento de coleta por aférese e ingestão de líquidos a verificação e manutenção da permeabilidade do acesso venoso, monitorização do hemograma e da bioquímica (compartilhados com a equipe médica, que prescreve reposições quando 
necessário), a ciência do número de células coletadas e continuidade do estímulo em caso de mais de uma coleta, mediante prescrição médica.

A partir do momento em que foram internados, os pacientes receberam o regime de condicionamento iniciado no D-5 antes do TCTH seguido da infusão das CTH. Posteriormente, ocorreu a alta hospitalar para continuidade de seu tratamento em regime ambulatorial. Devido às altas doses de quimioterapia recebidas no condicionamento, os pacientes apresentam sintomatologia em graus variados que podem ou não inviabilizar sua permanência no ambulatório. As toxicidades ao regime de condicionamento incluem náuseas, vômito, mucosite e diarreia e constitui uma das principais causas de morbi-mortalidade pós-TCTH (Scott et al., 1988). A mucosite gastrointestinal é geralmente a toxicidade não-hematológica mais importante (Anastasia et al., 2009) e presente em 69 (69\%) pacientes da nossa amostra, na sua maioria nos graus I a II, sendo bem manejada no ambulatório, visto que apenas um paciente necessitou de internação por apresentar mucosite grau IV.

Nesta casuística, 62 (62\%) pacientes apresentaram diarréia nos graus I e II, 61 (61\%) pacientes apresentaram náusea e êmese, 58 (58\%) pacientes apresentaram mucosite nos graus de I a II.

Em um estudo realizado com 297 pacientes adultos, consecutivos, portadores de MM, LNH, LH e LMA em diferentes estágios, tipo, resposta e número de tratamentos prévios, que foram submetidos ao ТCTHa, foi visto que dentre os principais resultados, a colite neutropênica foi mais frequente nos pacientes portadores de $\mathrm{LNH}$ e que tinham recebido como regime de condicionamento o protocolo BEAM, porém com doses modificadas de citarabina e etoposide. É sabido que ambos agentes induzem a um dano na mucosa do trato gastrointestinal e eventual 
colite neutropênica (Gil et al., 2007). Os dados são concordantes com a casuística deste estudo, onde dos 36 pacientes submetidos ao regime BEAM 400 e dos dez pacientes submetidos ao condicionamento BEAM, 31/46 (67,39\%) pacientes, independente da graduação, apresentaram diarreia. Dez pacientes submetidos ao regime de condicionamento internaram com queixa de dor aguda com distensão abdominal, sugerindo diagnóstico clínico de colite neutropênica. Dentre os dez pacientes, nove foram submetidos ao regime de condicionamento BEAM 400 e apenas um ao BEAM.

No nosso estudo, a mediana de alta hospitalar dos pacientes foi de um dia após a infusão das CTH. Nesta fase, os efeitos decorrentes da toxicidade ao regime de condicionamento ainda estão por vir e serão administrados no ambulatório, onde os pacientes permanecem parte do seu dia e posteriormente retornam para casa ou para a casa de apoio. Os enfermeiros devem discutir com os pacientes e cuidadores o que esperar ao longo das próximas duas semanas, incluindo pancitopenia com frequentes alteração da mucosa e controle da dor (Toreend et al., 2007) e também devem avaliar os pacientes com relação à fadiga, ansiedade, insônia, perda de apetite, mucosite, náuseas e vômitos, que estão entre os sintomas mais comumente relatados durante o TCTH (Hacker, 2003). Os enfermeiros são profissionais essenciais na avaliação contínua dos sintomas e também responsáveis pelas intervenções de enfermagem baseadas em evidências (Toreend et al., 2007). Os sintomas podem afetar a qualidade de vida dos pacientes (Hann et al., 1999; Marks et al., 1999). No contexto da alta hospitalar precoce, o enfermeiro deve estar mais atento e valorizar as queixas e relatos do paciente, afim de minimizar possíveis ocorrências no período em que o paciente permanece em ambiente extra-hospitalar, orientando o paciente e treinando 
o cuidador na identificação e busca de auxílio profissional em caso de alterações. A detecção e o acompanhamento da graduação das toxicidades também deve ser bastante precisa, visto que a atenção dada a esta intercorrência levou à intervenção precoce em caso de agravamento e necessidade de internação.

Após o uso da quimioterapia mieloablativa, a toxicidade da mucosa e as citopenias prolongadas podem levar a um risco significativo de complicações infecciosas (Solomon et al., 2010). A infecção representa 8\% das causas primárias de morte nos pacientes submetidos ao TCTHa (Tomblyn et al., 2009). A pancitopenia é de longa duração e restabelecida através da infusão das CTH, sendo responsável por 5 a $10 \%$ da mortalidade relacionada ao regime mieloablativo (Pai et al., 2010). Ainda sobre os regimes mieloablativos, um estudo realizado por Mank; Van Der Lelie (2003a) avaliou a infecção e mortalidade demonstrando que este procedimento é possível sem que os pacientes permaneçam confinados e isolados no hospital e, portanto, permitido alta precoce. A neutropenia febril frequentemente tem duração de três semanas ou mais (Kern, 2005) e esteve presente nesta amostra em 58\% dos pacientes até a enxertia medular, um número menor comparado aos 97,39\% descrito na literatura referente à pacientes sob regime de internação (Santos et al., 2012). Neste estudo, as complicações infecciosas foram estudadas até o trigésimo dia pósTCTHa devido a maior incidência neste período, com predominância de bactérias gram positivas (Kapur et al., 2000). Alguns fatores podem contribuir para o aumento da incidência de infecção, incluindo o uso de cateter venoso central (Kapur et al., 2000; Mendes et al., 2012), regime de condicionamento (Gil et al., 2007;), quebra da barreira mucocutânea ocasionado pela mucosite (Mendes et al., 2012). 
Em um estudo brasileiro realizado por Santos et al. (2012) foram analisados retrospectivamente 112 pacientes internados e submetidos ao TCTHa que apresentaram neutropenia febril em relação ao perfil infeccioso e aos fatores de risco associados. Como resultados obtiveram: infecção em 57,2\% dos pacientes neutropênicos, a infecção de CVC foi a principal causa (25,9\%). A prevalência foi de bactérias gram positivas com predomínio da bactéria Staphylococcus coagulase negativo, porém as bactérias gram negativas causaram maior taxa de morte (Santos et al., 2012).

Em outro estudo, previamente realizado em nosso Serviço, que avaliou pacientes portadores de leucemia mielóide crônica submetidos ao TCTH alogênico, não foram observadas diferenças nos resultados das culturas entre os pacientes submetidos ao TCTH ambulatorial e internados, exceto para Pseudomonas aeruginosa (Nicolau et al., 2007b). Outros estudos apresentaram menor incidência de infecções por bactérias multirresistentes nosocomiais quando comparado aos pacientes tratados em unidade de internação (Ferrara et al., 2004; Svahn et al., 2008).

No nosso estudo, $23 \%$ dos pacientes apresentaram infecção documentada por presença de micro-organismo nas culturas e assim como no estudo de Santos et al. (2012) que foi realizado com os pacientes sob regime de internação, a infecção por bactérias gram positivas foi prevalente, com predomínio de infecções por Staphylococcus coagulase negativo e Enterococcus sp.

O Staphylococcus é uma a bactéria gram positiva prevalente nas complicações infecciosas relacionadas ao TCTH, a espécie mais comumente encontrada é o coagulase negativo. (Malgorzata et al, 2009; Wingard et al., 2011) 
Os Enterococcus sp são bactérias comensais do trato gastrointestinal, vaginal e da cavidade oral. Os Enterococcus resistentes à vancomicina são um dos principais patógenos que causam infecções hospitalares, e atualmente sua presença é notável em infecções urinárias, de sítio cirúrgico e bacteremias (Ghanem et al., 2007). Os $E$. faecalis e E. faecium constituem $80-90 \%$ e $10-15 \%$, respectivamente, de todas as espécies de Enterococcus isolados em culturas (Jett et al.,1994). A incidência de $E$. faecium, principalmente resistente à fármacos, aumenta significantemente nos pacientes submetidos ao transplante de órgãos, portadores de leucemia aguda e neutropênicos (Kapur et al., 2000). A morbidade e mortalidade causadas por infecção ocorrem principalmente durante os três primeiros meses pós-TCTH, período necessário para a reconstrução hematológica (Marena et al., 2001).

Gilbert et al. (1994) relata que na fase de neutropenia a profilaxia antimicrobiana deve ser intensificada, para que a incidência de febre possa ser reduzida de valores $>90 \%$ para $<60 \%$. Fernández-Ávilez et al., (2006) relata que o uso de antibióticos a partir do D+1 pós-TCTH é recomendado sob a hipótese de que haveria uma redução nas taxas de infecção por bactérias e diminuição na necessidade de hospitalização. A alta hospitalar precoce é um procedimento que pode diminuir o risco de infecção nosocomial (Fernández-Ávilez et al., 2006) em decorrência da diminuição da exposição do paciente ao ambiente hospitalar. A baixa incidência de infecção até o $\mathrm{D}+30$ pode estar relacionada à alta precoce e também à profilaxia antimicrobiana empregada neste serviço. Neste contexto relacionado à infecção, a enfermagem deve implementar práticas que previnam e controlem as infecções relacionadas ao TCTH (Bevans et al., 2009). 
Os resultados do estudo demonstraram ainda que, os pacientes submetidos ao TCTHa com alta hospitalar precoce, durante a fase de aplasia medular, não apresentaram aumento na mortalidade, expresso por dois $(2 \%)$ pacientes que foram a óbito por causas infecciosas durante os 60 primeiros dias após o TCTH, sendo que um não apresentava enxertia medular.

Como já discutido, os regimes mieloablativos causam intensa pancitopenia com duração de uma a três semanas após sua administração. Neste período é necessário que sejam transfundidos concentrados de hemácias e plaquetas na tentativa de manter as funções orgânicas estáveis. No nosso estudo, a mediana de enxertia de granulócitos após o TCTHa com alta hospitalar precoce foi de 12 dias e de plaquetas, 15 dias, com mediana de transfusões até a alta do serviço de três concentrados de hemácias e quatro concentrados de plaquetas.

Quando confrontados os dados da literatura sobre o TCTH realizado sob regime de internação e o TCTH ambulatorial, os dados obtidos nesta casuística relacionados ao tipo de mobilização, número de células CD34+ infundidas, tempo de enxertia, tempo de aplasia, não apresentaram diferenças entre o paciente que permaneceu internado para TCTH e aquele que recebera, o TCTHa sob regime de alta precoce demonstrando a factibilidade da realização desta modalidade de tratamento.

$\mathrm{Na}$ amostra estudada, 23 (23\%) pacientes necessitaram de internação hospitalar em algum momento desde a alta hospitalar após o transplante até o momento de sua alta para acompanhamento no Serviço de origem.

Em relação à frequência das internações, quatro pacientes internaram por até três vezes totalizando 28 episódios de internação. Dos 28 episódios de internação, 19 
foram realizadas no período de aplasia, sendo dez pacientes internados por toxicidade ao regime de condicionamento $(10 / 19 ; 52,63 \%)$ e quatro por infecção (4/19; 21\%). Ferrara et al (2004) afirmaram que 64\% dos pacientes não necessitam de internação pós-TCTH. Neste estudo, os pacientes foram assistidos satisfatoriamente no ambulatório, seguindo o esquema de alta hospitalar precoce, fundamentados nos 59 (59\%) pacientes que receberam alta hospitalar precoce no D+1 e também pelos $77 \%$ dos pacientes que tiveram seus tratamentos bem conduzidos no ambulatório e sem a necessidade de internação.

\subsection{Considerações}

Este estudo retrospectivo demonstra a viabilidade da modalidade de TCTH com alta hospitalar precoce, bem como a necessidade de uma equipe de enfermagem especializada no ambulatório, que atenda aos quesitos de prevenção, orientação e intervenção.

As orientações ao paciente podem contribuir para o aumento da adesão ao tratamento medicamentoso, prevenção das complicações relacionadas ao tratamento e permite que o paciente tenha maior autonomia nas decisões acerca de seu tratamento e no controle da sua vida (Khera et al., 2011; Kirsch et al., 2012).

As condições econômico-culturais muitas vezes são fatores determinantes para o sucesso do tratamento. A carta de direito dos usuários do SUS determina que todo cidadão tem direito a tratamento adequado e efetivo ao seu problema, mas não há 
possibilidade de sucesso em um tratamento de grande complexidade como é o TCTH sem que haja uma estrutura adequada que possibilite o procedimento. O auxílio da casa de apoio aos pacientes e cuidadores ultrapassa a necessidade do alojamento, sendo necessárias condições estruturais, física e até psíquicas por parte dos colaboradores que necessitam compreender a importância dos procedimentos adequados aos imunossuprimidos para que as infecções não sejam transferidas do ambiente hospitalar para outra área de convivência de pacientes.

O sucesso dos programas de TCTH com alta hospitalar precoce está no fato de que podem ser prevenidas as rupturas familiares causadas pelas internações prolongadas na tentativa de melhorar a qualidade de vida (Meisenberg et al., 1998b). Em contra partida, a estrutura hospitalar composta por equipe multi-profissional com experiência neste perfil de pacientes, estrutura física, medicações e estrutura social são indispensáveis para que os pacientes permaneçam no seu convívio e na sua rotina.

Apesar da necessidade de admissão de um determinado número de pacientes que receberam alta hospitalar precoce (principalmente devido à toxicidade ao regime de condicionamento), o tempo de permanência internado pode ser significativamente reduzido (Meisenberg et al., 1998b).

No decorrer dos anos, o desenvolvimento de novas técnicas, medicamentos, a atenção à qualidade e segurança, a criação de protocolos e fluxos de atendimento ao paciente, tem acrescentado na viabilidade dessa modalidade de tratamento permitindo que a alta precoce seja segura.

A factibilidade desta modalidade é expressa pelos resultados obtidos nesta amostra, evidenciado pelo baixo índice de infecção e melhor manejo das toxicidades. 
Estudos relacionados à qualidade de vida são necessários para inferir outras questões que não foram abordadas nesta análise. 
7. CONCLUSÕES 
- A equipe de enfermagem apresenta papel fundamental no contexto da alta hospitalar precoce na conduta e manejo dos pacientes.

- O Enfermeiro participou na orientação e condutas durante a fase de mobilização, transplante e acompanhamento ambulatorial.

- A mediana de tempo para enxertia medular foi de 12 dias e durante a fase de aplasia os pacientes evoluíram bem, com baixa internação e infecção.

- Houve baixa incidência de complicações e internações, sendo a toxicidade ao regime de condicionamento a maior causa de internação.

- As toxicidades ao regime de condicionamento apresentadas foram bem manejadas em regime ambulatorial também pela Equipe de enfermagem.

- Durante a fase de mobilização, os pacientes coletaram as CTH em mediana de uma coleta e não houve insucesso da mobilização e na coleta das CTH. 


\section{REFERÊNCIAS BIBLIOGRÁFICAS}


1. Anastasia A, Giglio F, Mazza R, Sarina B, Todisco E, Bramanti S, Castagna L. Early discharge after high-dose melphalan and peripheral blood stem cell reinfusion in patients with hematological and non-hematological disease. Leuk Lymphoma. 2009; 50(1): 80-4.

2. Appelbaum FR. The use of bone marrow and peripheral blood stem cell transplantation in the treatment of cancer. CA Cancer J Clin. 1996; 46(3): 14264.

3. Armitage JO. The history of autologous hematopoietic cell transplantation. In: Appelbaum FR, Forman SJ, Negrin RS, Blume KG, editors. Thomas hematopoietic cell transplantation. 4th ed.: Wiley-Blackwell; 2009. Chap 2, p. 8-14.

4. Arslan Ö, Moog R. Mobilization of peripheral blood stem cells. Transfus Apher Sci. 2007; 37(2): 179-85.

5. Bacigalupo A, Ballen K, Rizzo D, Giralt S, Lazarus H, Ho V, Sandmaier BM, Barrett J, Blaise D, Lowski R, Horowitz M. Defining the intensity of conditioning definitions. Biol Blood Marrow Transplant. 2009; 15(12): 162833.

6. Bakken AN. Cryopreserving human peripheral blood progenitor cells. Curr Stem Cell Res Ther. 2006; 1(1): 47-54.

7. Bhatia S, Robison LL, Francisco L, Carter A, Liu Y, Grant M, Baker KS, Fung H, Gurney JG, McGlave PB, Nademanee A, Ramsay NKC, Stein A, Weisdorf DJ, Forman SJ. Late mortality in survivors of autologous hematopoietic-cell transplantation: report from the Bone Marrow Transplant survivor study. Blood. 2005; 105(11): 4215-22.

8. Bearman By SL, Appelbaum FR, Buckner CD, Petersen FB, Fisher LD, Clift RA, Thomas ED. Regimen-related toxicity in patients undergoing bone marrow transplantation. $1988 ; 6(10): 1562-8$.

9. Bevans M, Tierney K, Bruch Coleen, Burgunder M, et al. Hematopoietic stem cell transplantation nursing: a practice variation study. Oncology Nurs Forum. 2009; 36(6): E317-25.

10. Bonassa EMA, Mancusi FCM. Transplante de medula óssea e de células-tronco hematopoiéticas. In: Bonassa EMA, Gato MIR, editoras. Terapêutica oncológica para enfermeiros e farmacêuticos. $4^{\mathrm{a}}$ ed. São Paulo: Atheneu; 2012. Cap. 9, p.489-517.

11. Brasil. Ministério da Saúde. Portaria $\mathrm{n}^{\circ} 2041$ tabela de procedimentos, medicamentos e OPM do SUS. Diário Oficial da União, Brasília. 28 de setembro de 2009. 
12. Brasil. Agência nacional de vigilância sanitária. Resolução Diretoria Colegiada da Agência Nacional de Vigilância Sanitária (ANVISA) n. 153 de 14 de Junho de 2004. Determina o regulamento técnico para os procedimentos hemoterápicos, incluindo a coleta, o processamento, a testagem, o armazenamento, o transporte de qualidade e uso humano de sangue e seus componentes, obtidos do sangue venoso, do cordão umbilical, da placenta e da medula óssea. Diário Oficial da União, Brasília.

13. Broers S, Kaptein AA, Le Cessie S, Fibbe W, Hegevelend, MW. Psycological functioning and quality of life following bone marrow transplantation: A threeyear follow-up study. J Psychosom Res. 2000; 48(1): 11-21.

14. Brown SL, Faltus KJ. Hematologic malignancy education for stem cell transplantation nurses. Oncol Nurs Forum. 2011; 38(4): 401-2.

15. Bueno ND, Duley FL, Saboya R, Amigo Filho JU, Coracin FL, Chamone D de A. Busulfan and melphalan as conditioning regimen for allogeneic hematopoietic stem cell transplantation in acute myeloid leukemia in first complete remission. Rev Bras Hematol Hemoter. 2011; 33(3): 179-84.

16. Buckner CD. Autologous bone marrow transplants to hematopoietic stem cell support with peripheral blood stem cells: a historical perspective. $J$ Hematother. 1999; 8: 233-6.

17. Champlin RE, Schmitz N, Horowitz MM, Chapuis B, Chopra R, Cornelissen JJ, Gale RP, Goldman JM, Loberiza FR Jr, Hertenstein B, Klein JP, Montserrat E, Zhang MJ, Ringdén O, Tomany SC, Rowlings PA, Van Hoef ME, Gratwohl A. Blood stem cells compared with bone marrow as a source of hematopoietic cells for allogeneic transplantation. IBMTR Histocompatibility and Stem Cell Sources Working Committee and the European Group for Blood and Marrow Transplantation (EBMT). Blood. 2000; 95(12): 3702-9.

18. CIBMTR - Center for International Blood and Marrow Transplant Research. Disponível em http://www.cibmtr.org/StatisticalSupport/Pages/index.aspx, acessado em 20-02-2012, às 23:37h.

19. Costa R, Padilha MI, Amante LN, Costa E, Bock LF. O legado de Florence Nightingale: uma viagem no tempo. Texto Contexto Enferm. 2009; 18(4): 6619.

20. Cortez AJP.Transplante autólogo de células-tronco hematopoiéticas nos pacientes com linfoma de Hodgkin: análise de 106 pacientes [tese]. São Paulo: Universidade de São Paulo; 2010.

21. Cottler-Fox M, Lapidot T, Petit I, Kollet O, DiPersio JF, Link D, Devine S. Stem cell mobilization. Hematology Am Soc Hematol Educ Program. 2003; 419-37. 
22. Das Mercês NNA; Erdmann AL. Enfermagem em transplante de células-tronco hematopoiéticas: produção científica de 1997 a 2007. Acta Paul Enfer. 2010; 23(2): 271-7.

23. DiPersio JF, Stadtmauer EA, Nademancee A, Micallef IN, Stiff PJ, Kaufman JL et al. Plerixafor and G-CSF versus placebo and G-CSF to mobilize hematopoietic stem cell for autologous stem cell transplantation in patients with multiple myeloma. Blood. 2009a:113(23): 5720-6.

24. DiPersio JF, Micallef IN, Stiff PJ, Bolwell BJ, Maziarz RT, Jacobsen E, Nademanee A, McCarty J, Bridger G, Calandra G. Phase III prospective randomized double-blind placebo-controlled trial of plerixafor plus granulocyte colony stimulating factor compared with placebo plus granulocyte colonystimulating factor for autologous stem-cell mobilization and transplantation for patients with non-Hodgkin's lymphoma. J Clin Oncol. 2009b; 27(28): 476773.

25. Dix SP, Geller RB. High-dose chemotherapy with autologous stem cell rescue in the outpatient setting. Oncology. 2000; 14(2): 171-85.

26. Durie BG, Harousseau JL, Miguel JS, Bladé J, Barlogie B, Anderson K, Gertz M, Dimopoulos M, Westin J, Sonneveld P, Ludwig H, Gahrton G, Beksac M, Crowley J, Belch A, Boccadaro M, Cavo M, Turesson I, Joshua D, Vesole D, Kyle R, Alexanian R, Tricot G, Attal M, Merlini G, Powles R, Richardson P, Shimizu K, Tosi P, Morgan G, Rajkumar SV. International uniform response criteria for multiple myeloma. Leukemia. 2006; 20(9): 1467-73.

27. Faucher C, Soriano AGLC, Esterni B,Vey N, Stoppa AM, Chabannon C, Mohty M, Michallet M, Bay JO, Genre D, Maraninchi D, Viens P, Moatti JP, Blaise D. Randomized study of early hospital discharge following autologous blood SCT: medical outcomes and hospital costs. Bone Marrow Transplant. 2012; 47(4): 549-55.

28. Fernández-Avilés F, Carreras E, Urbano-Ispizua A, Roriva M, Martínez C, Gaya A, Granell M, Ramiro L, Gallego C, Hernando A, Segura S, García L, González M, Valverde M, Montserrat E. Case-control comparision of at-home to total hospital care for autologous stem-cell transplantation for hematologic malignancies. J Clin Oncol. 2006; 24(30): 4855-61.

29. Ferrara F, Palmieri S, Viola A, Copia C, Schiavone EM, De Simone M, Pocali B, D' Amico MR, Annunziata M, Mele G. Outpatient-based peripheral blood stem cell transplantation for patients with multiple myeloma. Haematol J. 2004. 5(3): 222-6.

30. Fife BL, Huster GA, Cornetta KG, Kennedy VN, Akard LP, Broun RE. Longitudinal study of adaptation to the stress of bone marrow transplant. J Clin Oncology. 2000; 18(7): 1539-49. 
31. Frey P, Stinson T, Siston A, Knight SJ, Ferdman E, Traynor A, Gara O, Rademaker A, Bennett C, Winter JN. Lack caregivers limits use of outpatient hematopoietic stem cell transplant program. Bone Marrow Transplant. 2002; 30: 741-8.

32. Ghanem G, Hachem R, Jiang Y, Chemaly RF, Raad I. Outcomes for and risk factors associated with vancomycin-resistant Enterococcus faecalis and vancomycin-resistant Enterococcus faecium bacteremia in cancer patients. Infect Control Hosp Epidemiol. 2007; 28(9): 1054-9.

33. Gil L, Styczynski J, Komarnicki. Infectious complication in 314 patients after high-dose therapy and autologous hematopoietic stem cell transplantation: risk factors analysis and outcome. Infection. 2007; 35(6): 421-7.

34. Gilbert C, Meisenberg B, Vredenburgh J, Ross M, Hussein A, Perfect J, Peters WP. Sequential prophylactic oral and empiric once-daily parenteral antibiotics for neutropenia and fever after high-dose chemotherapy and autologous bone marrow support. J Clin Oncol. 1994; 12(5): 1005-11.

35. Goldman JM, Horowitz MM. The International Bone Marrow Transplant Registry. Int J Hematol, 2002; 76(1): 393-7.

36. Gordan LN, Sugrue MW, Lynch JW, Williams KD, Khan SA, Wingard JR, Moreb JS. Poor mobilization of peripheral blood stem cells is a risk factor for worse outcome in lymphoma patients undergoing autologous stem cell transplantation. Leuk Lymphoma. 2003; 44(5): 815-20.

37. Grant M, Cooke L, Bhatia S, Forman SJ. Discharge and unscheduled readmissions of adult patients undergoing hematopoietic stem cell transplantation: implications for developing nursing interventions. Oncol Nurs Forum. 2005; 32(1); E1-8.

38. Grotto HZW, Noronha JFA. Identificação de células-tronco hematopoiéticas: citometria de fluxo convencional versus contador hematológico automatizado. Rev Bras Hemato. Hemoter. 2003; 25: 169-72.

39. Hacker, ED. Quantitative measurement of quality of life in adult patients undergoing bone marrow transplant or peripheral blood stem cell transplant: A decade in review. Oncol Nurs Forum. 2003; 30(4): 613-29.

40. Hann DM, Garovoy N, Finkelstein B, Jacobsen PB, Azzarello LM, Fields KK. Fatigue and quality of life in breast cancer patients undergoing autologous stem cell transplantation: A longitudinal comparative study. J Pain Symptom Manage. 1999; 17(5): 311-19.

41. Hansen JA, Gooley TA, Martin PJ, Appelbaum F, Chauncey TR, Clift RA, Petersdorf EW, Radich J, Sanders JE, Storb RF, Sullivan KM, Anasetti C.Bone marrow transplants from unrelated donors for patients with chronic myeloid leukemia. N Engl J Med. 1998; 338(14): 962-8. 
42. INCA - Instituto Nacional do Cancer, disponível em http://www2.inca.gov.br/wps/wcm/connect/agencianoticias/site/home/noticias/ 2011/brasil_bate_recorde_em_doacao_orgaos), acessado em 13-02-2012, às 23 horas.

43. Jagannath S, Vesole DH,Zhang M, Desikan KR, Copeland N, Jagannath M, Bracy D, Jones R, Cowley J, Tricot G, Barlogie B. Bone Marrow Transplant. 1997; 20(6): 445-50.

44. Jagasia MH, Savani BN, Neff A, Dixon S, Chen H, Pickard AS. Outcome, toxicity and cost analysis of autologous stem cell mobilization. Bone Marrow Transplant. 2011; 46(8): 1084-8.

45. Jantunen E, Varmavuo V, Juutilainen A, Kuittinen T, Mahlamäki E, Mäntymaa P, Nousiainen T. Kinetics of blood CD34(+) cells after chemotherapy plus GCSF in poor mobilizers: Implications for pre-emptive plerixafor use. Ann Hematol. 2012; 91(7): 1073-9.

46. Jett BD, Huycke MM, Gilmore MS. Virulence of Enterococci. Clin Microbiol Rev. I. 1994; 7(4): 462-78.

47. Jones JA, Qazilbash MH, Shih Y-CT, Cantor SB, Cooksley CD, Elting LS. Inhospital complication of autologous stem cell transplantation for lymphoid malignancies. Cancer. 2008; 112(5): 1096-105.

48. Kapur D, Dorsky D, Feingold JM, Bona RD, Edwards RL, Aslanzadeh J, Tutschka PJ, Bilgrami S. Incidence and outcome of vancomycin-resistant enterococcal bacteremia following autologous peripheral blood stem cell transplantation. Bone Marrow Transplant. 2000; 25(2): 147-52.

49. Keogh FO, Riordan J, McNamara C, Duggan C, Mc Cann SR. Psychosocial adaptation of patients and families following bone marrow transplantation: A prospective, longitudinal study. Bone Marrow Transplant. 1998; 22(9): 905-11.

50. Kern WV. Outpatient management in patients with neutropenia after intensive chemotherapy-is it safe? Ann Oncol. 2005; 16(2): 179-180.

51. Khera N, Chow EJ, LeisenringWM, Syrjala KL, Baker KS, Flowers ME, Martin PJ, Lee SJ. Factors associated with adherence to preventive care practices among hematopoietic cell transplantation survivors. Biol Blood Marrow Transplant. 2011; 17(7): 995-1003.

52. Kirsch M, Crombez P, Calza S, Eeltink C, Johansson E. Patient information in stem cell from the perspective of health care profissionals: A survey from the Nurses Group for blood and marrow transplantation. Bone Marrow Transplant. 2012; 47(8): 1131-3. 
53. Körbling M, Dörken B, Ho AD, Pezzutto A, Hunstein W, Fliedner TM. Autologous transplantation of blood-derived hemopoietic stem cells after myeloablative therapy in a patient with Burkitt's lymphoma. Blood. 1986; 67(2): 529-32.

54. Kuittinen T, Nousiainen T, Halonen P, Mahlamäki E, Jantunen E. Prediction of mobilization failure in patients with non-Hodgkin's lymphoma. Bone Marrow Transplant. 2004; 33(9): 907-12.

55. Lipe BC, Lansigan F, Gui J, Meehan K. Bone marrow transplantation for multiple myeloma: impact of distance from the transplant center. Clin Adv Hematol Oncol. 2012; 10(1): 28-32.

56. Loberiza FR Jr, Zhang MJ, Lee SJ, Klein JP, Lemaistre CF, Serna DS, Eapen M, Bredeson CN, Horowitz MM, Rizzo JD. Association of transplant center and physician factors on mortality after hematopoietic stem cell transplantation in the United States. Blood. 2005; 105(7): 2979-87.

57. Malgorzata M, Del Bono V, Raiola AM, Bruno B, Gualandi F, Occhini D, Di Grazia C, Frassoni F, Bacigalupo A, Viscoli C. Blood stream infection in allogenic hematopoietic stem cell transplant recipients: reemergence of grampositive rods and increasing antibiotics resistance. Biol Blood Marrow Transplant. 2009; 15(1): 47-53.

58. Malik S, Bolwell B, Rybicki L, Copelan O, Duong H, Dean R, Sobecks R, Kalaycio M, Sweetenham J, Pohlman B, Andresen S, Tench S, Koo A, Figueroa P, Copelan E. Apheresis days required for harvesting CD34+ cells predicts hematopoietic recovery and survival following autologous transplantation. Bone Marrow Transplant. 2011; 46(12): 1519-25.

59. Mank A, Van Der Lelie J. Is there still an indication for nursing patients with prolonged neutropenia in protective isolation? An evidence-based nursing and medical study of 4 years experience for nursing patients with neutropenia without isolation. Eur J Oncol Nurs. 2003a; 7(1): 17-23.

60. Mank A, Van Der Lelie J, Vos Rien de, Kersten MJ. Safe early discharge for patients undergoing high dose chemotherapy with or without stem cell transplantation: a prospective analysis of clinical variables predictive for complications after treatment. J Clin Nurs. 2010b; 20(3-4): 388-95.

61. Marena C, Zecca M, Carenini ML, Bruschi A, Bassi ML, Olivieri P, Azzaretti $\mathrm{S}$, Locatelli F. Incidence of, and risk factors for, nosocomial infections among hematopoietic stem cell transplantation recipients, with impact on procedurerelated mortality. Infect Control Hosp Epidemiol. 2001; 22(8): 510-7.

62. Marks DI, Gale DJ, Vedhara K, Bird JM. A quality of life study in 20 adult long-term survivors of unrelated donor bone marrow transplantation. Bone Marrow Transplant. 1999; 24(2): 191-5. 
63. McCann S; Schwenkglenks S, Bacon P, Einsele H, D’Addio A, Maertens J, Niederwieser D, Rabitsch W, Roosaar A, Ruutu T, Schouten H, Stone R, Vorkurka S, Quinn B, Blijlevens N. The prospective oral mucositis audit: relationship of several oral mucositis with clinical and medical resource use outcomes in patients receiving high-dose melphalan or BEAM-conditioning chemotherapy and autologous SCT. Bone Marrow Transplant. 2009; 43(2): 141-47.

64. Meisenberg BR, Miller WE, McMillan R, Callaghan M, Sloan C, Brehm T, Kosty MP, Kroener J, Longmire R, Save A, Piro LD. Outpatient high-dose chemotherapy with autologous stem cell rescue for hematologic and non hematologic malignances. J Clin Oncol. 1997a; 15(1): 11-7.

65. Meisenberg BR, Ferran K, Hollenbach K, Brehm T, Jollon J, Piro LD. Reduced charges cost associated with outpatient autologous stem cell transplantation. Bone Marrow Transplant. 1998b; 21(9): 927-32.

66. Mendes ET, Dulley F, Basso M, Batista MV, Coracin F, Guimarães T, Shikanai-Yasuda MA, Levin AS, Costa SF. Healthcare-associated infection in hematopoietic stem cell transplantation patients: risk factors na impact on outcome. Int J Infect Dis. 2012;16(6): 424-8.

67. Mendrone Jr A. Coleta de Células progenitoras hematopoéticas de sangue periférico após a administração de ciclofosfamida e fator de estímulo de colônia de granulócitos (G-CSF): uma análise de 307 pacientes [tese]. São Paulo: Universidade de São Paulo; 2007a.

68. Mendrone Jr A, Arrais CA, Saboya R, Chamone D de A, Dulley FL. Factors affecting hematopoietic progenitor cell mobilization: an analysis of 307 patients. Transf Apher Sci. 2008b; 39(3): 187-92.

69. Mendrone Jr A. Sangue periférico como fonte de células para terapia celular. Rev. Bras. Hematol. Hemoter. 2009c; 31(1): 19-24.

70. Miller AB, Hoogstraten B, Staqued M, Winkler A. Reporting results of cancer treatment. Cancer. 1981; 47: 207-14.

71. Mohty M, Ho AD. In an out of the niche: perspectives in mobilization of hematopoietic stem cell. Exp Hematol. 2011; 39(7): 723-9.

72. Morabito F, Martino M, Stelitano C, Oliva E, Kropp Mariagrazia, Irrera G, Console G, Fujo M, Messina G, Molica S, Callea V, Iacopino P. Feasibility of a mixed inpatient-outpatient model of peripheral blood stem cell transplantation for multiple myeloma. Haematologica. 2002; 87(11): 1192-9.

73. Murphy WJ, Artz AS, Champlin RE, Koreth J, Longo DL. Blood stem cell transplantation in older patients. Biol Blood Marrow Transplantation. 2009; 15(12): 1638-39. 
74. Moya R, Espigado I, Parody R, Carmona M, Marquez F, De Blas JM. Evaluation readmissions in hematopoietic stem cell transplant recipients. Transplant Proc. 2006; 38(8): 2591-92.

75. Nicolau JE. O Transplante de Medula Óssea Alogênico de Curto Período de Internação [tese]. São Paulo: Universidade de São Paulo; 2004a.

76. Nicolau JE, de Melo LMMP, Sturaro D, Saboya R, Dulley FL. Evaluation of early discharge after allogenic bone marrow transplantation for chronic myeloid leukemia. São Paulo Med J. 2007b; 125: 174-9.

77. Ozcelik T, Topcuoglu P, Beksac M, Ozcan M, Arat M, Biyikli Z, Bakanay SM, Ilhan GG, Arslan Ö, Demirer T. Mobilization of PBSCs with chemotherapy and recombinant human G-CSF: a randomized evaluation of early vs late administration of recombinant human G-CSF. Bone Marrow Transplant. 2009; 44(12): 779-83.

78. Özkurt ZN, Yegin ZA, Suyani E, Aki SZ, Acar Kadi, Yaci M, Sucak GT. Factors affecting stem cell mobilization for autologous hematopoietic stem cell transplantation. J Clin Apher. 2010; 25(5): 280-6.

79. Padilha MICS, Mancia JR. Florence Nigthingale e as irmãs de caridade: revisando a história. Rev Bras Enferm; 2005; 58(6): 723-6.

80. Pai V, Fernandez SA, Laudick M, Rosselet R, Termuhlen A. Delayed administration of filgrastim (G-CSF) following autologous peripheral blood stem cell transplant (PBSCT) in pediatric patients does not change time to neutrophil engraftment and reduces use of G-CSF. Pediatr Blood Cancer. 2010; 54: 728-33.

81. Peters WP, Ross M, Vrendenburgh JJ, Hussein A, Rubin P, Dukelow K, Cavanaugh C, Beauvais R, Kasprzak S. The use of intensive clinic support to permit outpatient autologous bone marrow transplantation for breast cancer. Semin Oncol. 1994; 21(7): 25-31.

82. Reiffers J, Bernard P, David B, Vezon G, Sarrat A, Marit G, Moulinier J, Broustet A. Successful autologous transplantation with peripheral blood hemopoietic cells in a patient with acute leukemia. Exp Hematol. 1986; 14: $312-5$.

83. Rimkus C. Acute complications of stem cell transplant. Semin Oncol Nurs. 2009; 25(2): 129-38.

84. Rosenbeck LL, Srivastava S, Kiel PJ. Peripheral blood stem cell mobilization tactics. The Ann Pharmacother. 2010; 44(1): 107-16. 
85. Rowlings PA, Passeweg JR, Armitage JO, et al. Current status of allogenic and autologous blood and marrow transplantation: report from the IBMTR and AMTR-North America. In: Lanza RP, Chick WL, editors. Yearbook of cell and Tissue Transplantation. Amsterdam: Kluwer Academic Publishers. 1996: 1934.

86. Salazar R, Solá C, Maroto P, Tabernero JM, Brunet J, Verger G, Valentí V, Cancelas JA, Ojeda B, Mendoza L, Rodríguez M, Montesinos J, López-López JJ. Infectious complications in 126 patients treated with high-dose chemotherapy and autologous peripheral blood stem cell transplantation. Bone Marrow Transplant. 1999; 23(1): 27-33.

87. Santos KB, Neto Hallack AE, Silva GA, Atalla A, Abreu MM, Ribeiro LC. Infection profile of patients undergoing autologous bone marrow transplantation in Brazilian institution. São Paulo Med J. 2012; 130(1): 10-6.

88. Sheppard D, Bredeson C, Allan D, Tay J. Systematic review of randomized controlled trials of hematopoietic stem cell mobilization strategies for autologous transplantation for hematologic malignances. Biol Blood Marrow Transplant. 2012; 18(8): 1191-203.

89. Solomon SR, Matthews RH, Barreras AM, Bashey A, Manion KL, McNatt K, Speckhart D, Connaghan DG, Morris Le Jr, Holland HK. Outpatient myeloablative allo-SCT: a comprehensive approach yields decreased hospital utilization and low TRM. Bone Marrow Transplant. 2010; 45(3): 468-75.

90. Ock SA, Rho GJ. Effect of dimethyl sulfoxide (DMSO) on cryopreservation of porcine mesenchymal stem cells (pMSCs). Cell Transplantation. 2011; 20(8): 1231-9.

91. Svahn BM, Remberger M, Heijebel M, Martell E, Wikstom M \& Eriksson B. Case-control comparison of at home and hospital care for allogenic hematopoetic stem-cell transplantation: the role of oral nutrition. Transplantation. 2008; 85(7): 1000-7.

92. Thomas ED. A history of bone marrow transplantation. In: Blume KG, Forman SJ, Appelbaum FR, editors. Thomas hematopoietic cell transplantation. 3th ed.: Wiley-Blackwell; 2007. Chap 1, p. 3-8.

93. To LB, Dyson PG, Branford AL, Russell JA, Haylock DN, Ho JQ, Kimber RJ, Juttner CA. Peripheral blood stem cells collected in very early remission produce rapid and sustained autologous haemopoietic reconstitution in acute non-lymphoblastic leukaemia. Bone Marrow Transplant. 1987a; 2(1): 103-8.

94. To LB, Haylock DN, Simmons PJ, Juttner CA. The biology and clinical uses of blood stem cells. Blood. 1997b; 89(7): 2233-58. 
95. Tomblyn M, Chiller T, Einsele H, Gress R, Sepkowitz K, Storek J, Wingard JR, Yoing J-AH, Boeckh MJ. Guidelines for preventing infections complications among hematopoietic cell transplant recipients: a global perspective. Bone Marrow Transplant. 2009; 44(8): 453-5.

96. Toreend E, Estrella SM, Rodriguez AL, Tariman JD. The role of high-dose chemotherapy supported by hematopoietic stem cell transplantation in patients with multiple myeloma: implications for nursing. Clin J Oncol Nurs. 2007; 11(4): 579-89.

97. Veiga KCG, Fernandes JD, Sadigursky D. Relacionamento enfermeira/paciente: perspectiva terapêutica do cuidado. Rev. enferm. UERJ. 2010; 18(2): 322-5.

98. Voltarelli JC, Ferreira E, Pasquini R. História do Transplante de células-tronco hematopoéticas no Brasil. In: Voltarelli JC, Pasquini R, Ortega ETT, editores. Transplante de células-tronco hematopoiéticas. São Paulo: Ed. Atheneu; 2009. Cap. 1, p. 15-42.

99. Vriesendorp HM. Aim of conditioning. Exp Hematol. 2003; 31(10): 844-54.

100. Wandt H, Schaefer-Eckart K, Frank M, Birkmann J, Wilhelm M. A therapeutic platelet transfusion strategy is safe and feasible in patients after autologous peripheral blood stem cell transplantation. Bone Marrow Transplant. 2006; 37(4): 387-92.

101. Watts MJ, Sullivan AM, Jamieson E, Pearce R, Fielding A, Devereux S, Goldstone AH, Lynch DC. Progenitor-cell mobilization after low-dose cyclophosphamide and granulocyte colony-stimulating factor: an analysis of progenitor-cell quantity and quality and factors predicting for these parameters in 101 pretreated patients with malignant lymphoma. J Clin Oncol. 1997; 15(2): 535-46.

102. Weaver CH, Schwartzberg L, Zhen B, Mangum M, Leff R, Tauer K, Rosenberg A, Pendergrass K, Kahwin P, Hainsworth J, Greco FA, West WH, Buckner CD. High-dose chemotherapy and peripheral blood stem cell infusion in patients with non-Hodgkins lymphoma: results of outpatient treatment in community cancer center. Bone Marrow Transplant. 1997; 20: 753-60.

103. Westermann AM, Holtkamp MMJ, Linthorst GAM, Van Leeuwen L, Willemse EJM, Van Dijk WC, Nooijen WJ, Baars JW. At home management of aplastic phase following high-dose chemotherapy with stem-cell rescue for hematological and non-hematological malignancies. Ann Oncol. 1999; 10(5): $511-7$.

104. Wingard JR, Hsu J, Hiemenz JW. Hematopoietic stem cell transplantation: an overview of infection risks and epidemiology. Hematol Oncol Clin North Am. 2011; 25(1): 101-16. 
105. Wuchter P, Ran D, Bruckner T, Schmitt T, Witzens-Harig M, Neben K, Goldschmidt H, Ho AD. Poor mobilization of hematopoietic stem celldefinitions, incidence, risk factors and impact on outcome of autologous transplantation. Biol Blood Marrow Transplant. 2010; 16(4): 490-9. 


\section{ANEXO I - Parecer de Aprovação do Comitê de Ética em Pesquisa}

\section{APROVAÇÃO}

A Comissáo de Ética para Análise de Projetos de Pesquisa CAPPesq da Diretoria Clínica do Hospital das Clínicas e da Faculdade de Medicina da Universidade de São Paulo, em sessão de 25/08/2010, APROVou ○ Protocolo de Pesquisa $n^{\circ}$ 0394/10, intitulado: "ANÁLISE DA MOBIUZAÇÃO E RESULTADOS DO TRANSPLANTE DE CÉLULAS TRONCO HEMATOPOÉTICAS AUTOGENICO (TCTHA) COM ALTA HOSPITALAR PRECOCE NOS PORTADORES DE DOENÇAS ONCO-HEMATOLÓGICAS." apresentado pelo Departamento de CLÍNICA MÉDICA.

Cabe ao pesquisador elaboror e apresentor à CAPPesq. os relatórios parciais e final sobre a pesquisa [Resoluçõo do Conselho Nacional de Saúde $n^{\circ}$ 196, de 10/10/1996, inciso IX.2, letra "c").

Pesquisador (a) Responsável: Frederico Luiz Dulley

Pesquisador (a) Executante: Alessandra Barban

CAPPesq, 26 de Agosto de 2010

Prot. Dr. Eduardo Massad Presidente da Comissāo de Éfica para Análise de Projetos de Pesquiso 